\title{
One-Dimensional Fluid-Structure Interaction Models in Pressurized Fluid-Filled Pipes: A Review
}

\author{
David Ferras $^{1, * \mathbb{D}}$, Pedro A. Manso ${ }^{2} \mathbb{D}$, Anton J. Schleiss ${ }^{2}$ and Dídia I. C. Covas ${ }^{3, *(\mathbb{D}}$ \\ 1 Department of Environmental Engineering and Water Technology, IHE Delft Institute for Water Education, \\ 2611AX Delft, The Netherlands \\ 2 Laboratory of Hydraulic Constructions (LCH), École Polytechnique Fédérale de Lausanne, \\ CH-1015 Lausanne, Switzerland; pedro.manso@epfl.ch (P.A.M.); anton.schleiss@epfl.ch (A.J.S.) \\ 3 CERIS, Instituto Superior Técnico, Universidade de Lisboa, 1049-001 Lisboa, Portugal \\ * Correspondence: d.ferras@un-ihe.org (D.F.); didia.covas@tecnico.ulisboa.pt (D.I.C.C.); \\ Tel.: +31-152-151-121 (D.F.)
}

Received: 3 September 2018; Accepted: 28 September 2018; Published: 8 October 2018

Featured Application: This research aims at providing an extensive literature review on the state-of-the-art numerical models in 1D Fluid-Structure Interaction (FSI). Readers will find especially useful the novel classification of FSI models, their governing equations and associated citations supporting further reading.

\begin{abstract}
The present review paper aims at collecting and discussing the research work, numerical and experimental, carried out in the field of Fluid-Structure Interaction (FSI) in one-dimensional (1D) pressurized transient flow in the time-domain approach. Background theory and basic definitions are provided for the proper understanding of the assessed literature. A novel frame of reference is proposed for the classification of FSI models based on pipe degrees-of-freedom. Numerical research is organized according to this classification, while an extensive review on experimental research is presented by institution. Engineering applications of FSI models are described and historical accidents and post-accident analyses are documented.
\end{abstract}

Keywords: hydraulic transients; water-hammer; fluid-structure interaction; degrees-of-freedom; junction coupling; Poisson coupling; friction coupling; Bourdon coupling.

\section{Introduction}

The first scientific contributions to the field of Fluid-Structure Interaction (FSI) in transient pipe flow took place in the 19th century when authors like [1,2] realized the need for considering both fluid compressibility and pipe-wall distensibility as interacting mechanisms. Classical water-hammer theory is also based on this principle. Since then, many researchers have added their contributions in a step-wise manner, building up and shaping the theory of hydraulic transients in pipe flow.

Software in the field of hydraulic transients is developed to cope with water-hammer waves, which are pressure waves associated with a sudden momentum change of fluid flow embedded in a closed-conduit. FSI models deal with the original principle of classical water-hammer theory, i.e., the consideration of water-hammer waves as a result of the relation between fluid and pipe deformations. A milestone was presented in [3] with a PhD thesis entitled 'An extension of the theory of water-hammer'. The basis of one-dimensional (1D) FSI was established, pipe vibration modes were described and the basic formulation for straight pipes was presented. Skalak's work triggered the FSI research on the two-way coupling between fluid dynamics and structural mechanics. Contributions by [4-12] developed and completed the theory for all the basic degrees-of-freedom (DOF) of pipe-systems. 
Some historical reviews on hydraulic transients in pipe flow are given by [13-18]. The developments in water-hammer research before the 20th century are well summarized by [19]. In addition, Refs. [20,21] presented in-depth reviews that served, at that time, as vision papers. More recently, Ref. [22] presented a complete state-of-the-art review focusing on both historic and most recent research and practice covering most of the water-hammer research topics. Surveys more specific in the field of Fluid-Structure Interaction are given by $[8,11,23]$ and, more recently, by [24]. The aim of the current review is to report the most significant contributions carried out in water-hammer research related to Fluid-Structure Interaction in 1D hydraulic transients modelling, giving emphasis on the time-domain analyses and focusing on the most recent research. A novel classification of FSI models based on pipe-degrees-of-freedom is presented.

The paper starts with the basic definitions and background theory that frame the research of FSI in water-hammer modelling. Numerical and experimental research is documented following the physics-based classification of pipe degrees-of-freedom. Finally, insights of engineering applications of Fluid-Structure Interaction developments in pipe flow are pointed out.

\section{Definitions and Basic Concepts}

\subsection{Fluid-Structure Interaction}

In the present review, Fluid-Structure Interaction in pipe systems is defined as the transfer of momentum and forces in both ways, between the pipe-wall and the contained fluid during unsteady flow [8]. Hence, FSI in pipe flow involves, at least, transient responses of two different physical systems. The interaction arises when the time scales of both system responses are shorter than the time scale of the overall transient event (i.e., time lag between the initial and the final steady state). If the disturbance source is shorter than both system responses, then fast fluid and solid transients simultaneously occur. If their interaction is strong enough, then the description of FSI might be worthwhile in water-hammer analyses and interaction mechanisms have to be taken into account.

In a broad sense, Fluid-Structure Interaction embraces any form of energy transfer, one upon another, between the fluid and the structure. In common engineering problems, this transferred energy is typically kinetic and elastic or thermal. The former is termed mechanical Fluid-Structure Interaction and the latter thermal Fluid-Structure Interaction. Heat exchange effects in transient pipe flow are barely significant, processes are assumed adiabatic, and FSI analyses are mainly focused on the momentum exchange between the fluid and the pipe structure.

Two different approaches may be followed to account for the momentum transfer into the structure [25]: considering that the structure moves as a rigid solid or by the propagation of a local excitation/deformation of the solid. In the first, no transient event is considered propagating throughout the solid, the structure element moves as a rigid body and its effect on the fluid is analysed. In the second, the modes of vibration of the structure element are excited and their respective transient states are taken into account and coupled with the fluid transient. The present review is focused only on the second form.

FSI analyses may be classified according to the dimensions and the degrees-of-freedom with which the pipe system is allowed to move. Normally, in 1D water-hammer analysis, the classification criterion is based on the modes of vibration of the pipe, which is quite convenient for frequency-domain approaches. However, for time-domain analyses, a classification based on the pipe degrees-of-freedom is more physically intuitive. The latter is the classification criterion used herein.

\subsection{Degrees-of-Freedom in Fluid-Filled Pipes}

Degrees-of-freedom (DOF) are the number of independent coordinates or parameters that describe the position or configuration of a mechanical system at any time [26]. Systems with a finite number of degrees-of-freedom are called discrete systems, and those with infinite degrees-of-freedom are called 
continuous systems. Pipe systems are continuous systems; however, these can be treated as discrete systems for numerical modelling purposes, with many DOFs depending on the number of nodes.

Pipes are slender elements; therefore, a 1D approach assuming that the fluid pressure propagates axially during hydraulic transients is reasonable. However, transient pressures transmit forces over the pipe wall that make the pipe system move in a 3D space. The basic degrees-of-freedom for a rigid body in a 3D space are three for translation (i.e., heaving, swaying and surging) and three for rotation (i.e., pitching, yawing and rolling). An infinitesimal control volume of a pipe-segment (like in Figure 1) will have the referred six basic degrees-of-freedom. The pipe-wall control-volume is a hollow cylinder; therefore, axisymmetric vibration due to hoop (circumferential) strain must be considered as well, adding another degree-of-freedom. Also called pipe breathing, this degree-of-freedom has to do with the radial displacements of the pipe-wall. Additionally, the infinitesimal control volume of the 1D contained fluid accounts for another degree-of-freedom. In other words, the fluid is indeed an inner coaxial cylinder with only one degree-of-freedom in the axial direction. Henceforth, in the present 1D FSI analysis, eight degrees-of-freedom compose the infinitesimal control volume of a pipe.

For each degree-of-freedom, momentum and mass conservation laws are applied, giving as a result a set of 16 partial differential equations (cf. Equations (1)-(16)), with time and space coordinates as independent variables, governing two basic dependent variables related with the loading and the movement in each degree-of-freedom (i.e., load and deformation relation). Depending on the pipe geometry, axial, shear, bending and torsional forces and displacements alternate throughout the pipe. A schematic of such displacements is shown in Figure 1.

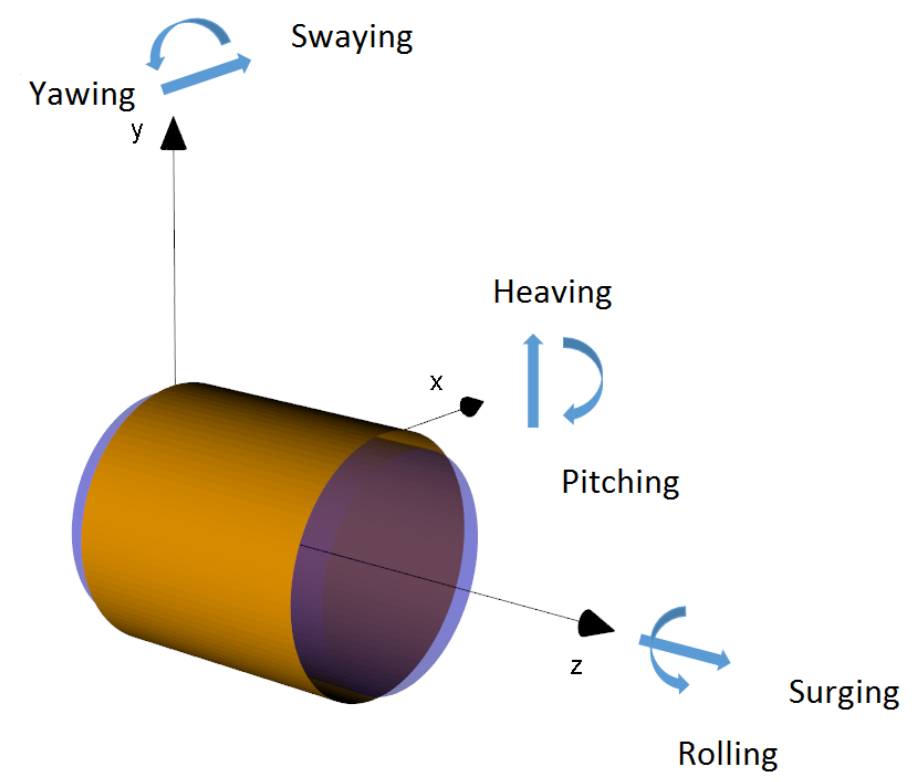

Figure 1. Spatial reference system and sign convention in a straight pipe element.

FSI models in 1D water-hammer analyses can be classified according to the pipe degrees-of-freedom as follows:

- $\quad$ 1-DOF (fluid surging): only the axial fluid transient event is described.

- 2-DOF (breathing): radial inertia of the fluid and the pipe are taken into account.

- 3-DOF (solid surging): refers to the axial movement of the pipe.

- 4-DOF (swaying): includes the effect of horizontal displacement of the pipe.

- 5-DOF (heaving): includes the effect of vertical displacement of the pipe.

- 6-DOF (yawing): includes the rotation of the pipe in the $\widehat{x} z$ plane.

- 7-DOF (pitching): includes the rotation of the pipe in the $\widehat{y} z$ plane.

- $\quad$ 8-DOF (rolling): includes the rotation of the pipe on the $\widehat{x y}$ plane. 


\subsection{Fundamental Formulae}

The equations of the system (Equations (1)-(16)) presented hereby correspond to the basic momentum and continuity conservation equations of a pipe-system with eight degrees-of-freedom, as the control volume depicted in Figure 1. Thin-wall assumption is adopted. Equations (1)-(6) and their associated characteristic equations can be found in [5]; Equations (7)-(16) in [7]. The symbols are declared in the Notation:

1-DOF (fluid surging):

$$
\begin{aligned}
& \frac{\partial V}{\partial t}+\frac{1}{\rho_{f}} \frac{\partial p}{\partial z}=0 \\
& \frac{1}{K} \frac{\partial p}{\partial t}+\frac{\partial V}{\partial z}=-\frac{2}{r} W
\end{aligned}
$$

2-DOF (breathing):

$$
\begin{aligned}
& \left(\rho_{p} r e+\rho_{f} \frac{r^{2}}{2}\right) \frac{\partial W}{\partial t}=r p-e \sigma_{\theta}, \\
& \frac{\partial \sigma_{\theta}}{\partial t}-E v \frac{\partial U_{z}}{\partial z}=E \frac{W}{r}
\end{aligned}
$$

3-DOF (solid surging):

$$
\begin{aligned}
& \frac{\partial U_{z}}{\partial t}-\frac{1}{\rho_{p}} \frac{\partial \sigma_{z}}{\partial z}=0 \\
& \frac{1}{E} \frac{\partial \sigma_{z}}{\partial t}-\frac{\partial U_{z}}{\partial z}=v \frac{W}{r}
\end{aligned}
$$

4-DOF (swaying):

$$
\begin{aligned}
& -\left(\rho_{p}+\frac{A_{f}}{A_{p}} \rho_{f}\right) \frac{\partial U_{x}}{\partial t}+\frac{\partial \sigma_{x}}{\partial z}=0, \\
& \frac{\partial \sigma_{x}}{\partial t}-G \frac{\partial U_{x}}{\partial z}=-G R_{y}
\end{aligned}
$$

5-DOF (heaving):

$$
\begin{aligned}
& -\left(\rho_{p}+\frac{A_{f}}{A_{p}} \rho_{f}\right) \frac{\partial U_{y}}{\partial t}+\frac{\partial \sigma_{y}}{\partial z}=0 \\
& \frac{\partial \sigma_{y}}{\partial t}-G \frac{\partial U_{y}}{\partial z}=-G R_{x}
\end{aligned}
$$


6-DOF (yawing):

$$
\begin{aligned}
& -\rho_{p} I_{p} \frac{\partial R_{y}}{\partial t}+\frac{\partial M_{y}}{\partial z}=-\sigma_{x} A_{p}, \\
& \frac{\partial M_{y}}{\partial t}-E I_{p} \frac{\partial R_{y}}{\partial z}=0,
\end{aligned}
$$

7-DOF (pitching):

$$
\begin{aligned}
& -\rho_{p} I_{p} \frac{\partial R_{x}}{\partial t}+\frac{\partial M_{x}}{\partial z}=\sigma_{y} A_{p} \\
& \frac{\partial M_{x}}{\partial t}-E I_{p} \frac{\partial R_{x}}{\partial z}=0
\end{aligned}
$$

8-DOF (rolling):

$$
\begin{aligned}
& -\rho_{p} J \frac{\partial R_{z}}{\partial t}+\frac{\partial M_{z}}{\partial z}=0, \\
& \frac{\partial M_{z}}{\partial t}-G J \frac{\partial R_{z}}{\partial z}=0 .
\end{aligned}
$$

Equations (1)-(16) describe, set-by-set, the uncoupled degrees-of-freedom, respectively, in terms of momentum and mass conservation. Hence, Equations (1) and (2) refer to the fluid flow and are based on pressure $(p)$ and flow velocity $(V)$, which are the dependent variables. Equations (3) and (4) describe the circumferential deformation of the pipe-wall, hence the main dependent variables are circumferential stress $\left(\sigma_{\theta}\right)$ and the radial velocity $(W)$ of the pipe-wall. Equations (5) and (6) describe the axial deformation of the pipe-wall, hence the main dependent variables are axial stress $\left(\sigma_{z}\right)$ and the axial velocity $\left(U_{z}\right)$ of the pipe-wall. Equations (7) and (8) refer to the horizontal shear of the pipe-wall and the main dependent variables are the shear stress $\left(\sigma_{x}\right)$ and the transversal velocity $\left(U_{x}\right)$. Equations (9) and (10) describe the vertical shear of the pipe-wall and, therefore, the main dependent variables are the shear stress $\left(\sigma_{y}\right)$ and the transversal velocity $\left(U_{y}\right)$ of the pipe-wall. Equations (11) and (12) refer to the horizontal bending of the pipe-wall, hence the main dependent variables are the horizontal bending moment $\left(M_{y}\right)$ and rotation $\left(R_{y}\right)$ of the pipe-wall. Equations (13) and (14) refer to the vertical bending of the pipe-wall, hence the main dependent variables are the vertical bending moment $\left(M_{x}\right)$ and rotation $\left(R_{x}\right)$ of the pipe-wall. Finally, Equations (15) and (16) describe the rotation over the pipe axis, hence the main dependent variables are the axial moment $\left(M_{z}\right)$ and rotation $\left(R_{z}\right)$ of the pipe-wall. According to the $1 \mathrm{D}$ and unsteady state assumptions, the independent variables for all the presented Equations (1)-(16) are space on the axial direction $(z)$ and time $(t)$.

All the degrees-of-freedom are distinguished in the previous system of equations, hence the analysis of wave celerities can be reduced to the essential (uncoupled) wave propagating speeds in each degree-of-freedom. The following formulae (Equations (17)-(21)) define the uncoupled wave celerities for each wave type considered (note that the sub-index refers to the DOF):

$$
\begin{aligned}
& a_{1}=\sqrt{\frac{K}{\rho_{f}}}, \\
& a_{3}=\sqrt{\frac{E}{\rho_{p}}},
\end{aligned}
$$




$$
\begin{gathered}
a_{4,5}=\sqrt{\frac{G A_{p}}{\rho_{p} A_{p}+\rho_{f} A_{f}}}, \\
a_{6,7}=\sqrt{\frac{E I_{p}}{\rho_{p} I_{p}+\rho_{f} I_{f}}}, \\
a_{8}=\sqrt{\frac{G}{\rho_{p}}} .
\end{gathered}
$$

Note that, due to the pipe axisymmetry, shear and bending wave celerities are equal in both planes (i.e., $a_{4}=a_{5}$ and $a_{6}=a_{7}$ ). Due to the dispersive nature of a 2-DOF wave propagating along the pipe-wall, no formula for $a_{2}$ is provided [18].

The advantage of considering the system of Equations (1)-(16) is that there is no need of considering the abstract concept of elastic wave celerity from classic water-hammer theory. An in-depth critical analysis of the different interpretations of wave speed in both time and frequency-domains is given by [27].

\subsection{Coupling Mechanisms and Modelling Approaches}

Pipe systems subjected to water-hammer transients can be regarded as free-damped-deterministic vibrating systems with multiple modes of vibration, coupled or uncoupled, according to the degrees-of-freedom of the conduit and exposed to skin friction, dry friction and structural/hysteretic damping. Although not included in Equations (1)-(16), these damping mechanisms convert hydraulic transients into non-periodic and nonlinear phenomena that are difficult to analyse.

The different degrees-of-freedom of a pipe system may interact one upon another. There are three basic kinds of coupling mechanisms [23]: (i) Poisson coupling describes the interaction between the axial motion of the pipe-wall and the pressure in the fluid occurring by means of the Poisson effect; (Poisson effect refers to the phenomenon in which a material compresses in the directions perpendicular to those in which the expansion occurs, and vice versa); (ii) friction coupling arises from the shear stress between the pipe-wall and the fluid; (iii) and junction coupling results from unbalanced local forces and by changes in the fluid momentum that occur in pipe bends, T-junctions or cross-section changes.

In time-domain analyses, the Method of Characteristics (MOC), the Finite Element Method (FEM), the Finite Difference Method (FDM) or the Finite Volume Method (FVM) are discretization methods used to solve the governing differential equations. Either a single or combined (hybrid) numerical method can be used for the description of the different degrees-of-freedom of the pipe. The method of characteristics (MOC) and the finite-element method (FEM), or a combination of both, are the most common numerical methods used for solving the one-dimensional basic equations [23]. One single integrating approach, such as MOC-MOC or FEM-FEM, is convenient as all the information flows into the same numerical scheme [11]. Other combinations are not that common in one-dimensional analyses; FVM is rather used for 3D simulations.

A different coupling approach consists of setting up an interaction between two different computer codes, one specific for the fluid and another for the structure. In each time-step, output information is transferred in both directions. There are contributions proposing methodologies to carry out this data transfer, such as [28]. However, the main challenge of this approach is the requirement of a considerable computational effort and data transfer [29].

An FDM code for the fluid and an FEM for the structure were coupled by [30] with the goal to simulate an interesting experimental research carried out at the Stanford Research Institute (SRI). Other authors who tried to simulate the same validating experiments are [31-33] who coupled FEM-FEM software. In addition, Refs. [34,35] used a FDM code for the fluid with an FEM for the structure with the goal to simulate field measurements from a pump shut-down and a closing valve in the nuclear power plant KRB II (Gundremmingen, Germany). MOC-FEM coupling was applied 
in $[36,37]$ aiming at describing the response of an experimental facility located at the Karlsruhe Nuclear Research Centre (KfK-Kernforschungszentrum Karlsruhe).

FEM and FVM are compared for the fluid domain simulation and coupling techniques are proposed in [38]. The traditional MOC approach for the fluid is compared with a CFD $k-\epsilon$ model in $[39,40]$, who coupled with an FEM model for the structure.

\section{Numerical and Experimental Research}

\subsection{Introduction}

A review of the numerical and experimental research of 1D FSI in the time-domain is presented hereby. Table 1 summarizes and describes the main FSI models according to their DOFs and lists some of the most relevant contributions that enabled the theoretical development, implementation, application and validation of numerical models using adapted versions of the fundamental equations presented in Section 2.3. Lists of relevant research contributions in 1D FSI are provided in Table A1 for research in numerical modelling and in Table A2 for experimental research. Details of these contributions are provided in the following subsections.

Table 1. Summary table of main 1D FSI models in hydraulic transients research.

\begin{tabular}{|c|c|c|}
\hline DOF & Description & Main Contributions \\
\hline 1 & $\begin{array}{l}\text { Only the fluid transient is described. } \\
\text { Equations solved: (1), (2) }\end{array}$ & {$[1,41-46]$} \\
\hline 1,3 & $\begin{array}{l}\text { Solid surging is coupled with the fluid. } \\
\text { Equations solved: (1), (2), (5), (6) }\end{array}$ & {$[12,47-57]$} \\
\hline $1,2,3$ & $\begin{array}{l}\text { Fluid, breathing and solid surging } \\
\text { interact. Equations solved: } \\
(1),(2),(3),(4),(5),(6)\end{array}$ & {$[5,47,58-60]$} \\
\hline 1,3 and 4,6 or 5,7 & $\begin{array}{l}\text { Fluid and solid surging, and either } \\
\text { swaying and yawing or heaving } \\
\text { and pitching are taken into account. } \\
\text { Equations solved: (1), (2), (5), (6) } \\
\text { and }(7),(8),(11),(12) \text { or }(9),(10),(13),(14)\end{array}$ & {$[40,53,61-68]$} \\
\hline $1,3,4,5,6,7,8$ & $\begin{array}{l}\text { Fluid and solid surging, swaying, } \\
\text { heaving, yawing, pitching and rolling } \\
\text { are coupled. Equations solved: } \\
(1),(2),(5),(6),(7),(8),(9),(10),(11),(12), \\
(13),(14),(15),(16)\end{array}$ & {$[51,69-74]$} \\
\hline
\end{tabular}

\subsection{One Degree-of-Freedom Models}

The classic water-hammer model (two-equation model) is a sophisticated version of the basic 1-DOF system (Equations (1) and (2)), where the right-hand side term of the continuity equation is adapted in order to account for the pipe-wall distensibility. Although the bulk modulus of compressibility and a finite acoustic wave speed are considered in the fluid, in terms of density variation, the fluid is assumed to be incompressible and pressure changes are related to velocity changes by embedding fluid compressibility and pipe-wall distensibility into the wave celerity value, which is regarded as a constant parameter and can be either experimentally or numerically determined. Research works such as $[1,42,46,75-78]$ contributed to the development of wave celerity formulae. The latest presented correcting factors to account for axial FSI.

The fundamental equations of classic water-hammer theory (i.e., mass and momentum conservation) can be derived from Navier-Stokes equations [79] or by directly applying the Reynolds Transport Theorem [80] to a control volume of the pipe. From an FSI standpoint, these fundamental equations can be also reached from the system of equations presented in Section 2, as the classical 
theory considers a combination of the first two degrees-of-freedom. The fundamental momentum conservation equation is directly the one presented in 1-DOF (Equation (1)). For mass conservation (continuity equation), the cross-sectional area of the control volume is assumed to vary and this variation is related to the fluid inner pressure by applying a quasi-static assumption in the 2-DOF. This derivation is described in Appendix B.

The system of partial differential equations (Equations (22) and (23)) represents the fundamental conservation equations of classic frictionless water-hammer theory:

$$
\begin{gathered}
\frac{\partial V}{\partial t}+\frac{1}{\rho_{f}} \frac{\partial p}{\partial z}=0 \\
\frac{\partial V}{\partial z}+\frac{1}{\rho_{f} a_{h}} \frac{\partial p}{\partial t}=0
\end{gathered}
$$

Usually, the system of mass conservation and momentum equations is solved by means of the Method of Characteristics (MOC), which is the most popular and extensively used method by researchers and engineers thanks to its easy programming, computational efficiency and accuracy of the results [81]. Over all methods, MOC stays the closest to the physics of the problem.

\subsection{Two Degree-of-Freedom Models}

The historical development of four-equation models can be traced back from [1] who already pointed out the need of considering axial stress waves. Pipe axial inertia and Poisson coupling was included qualitatively in the analyses of [82,83]. Lamb's work was extended in [3], who presented the four basic fundamental equations and introduced the concept of precursor waves. From an experimental standpoint [84] was the first to observe precursor waves, which are, at the same time, the evidence of the Poisson coupling effect. Finally, Refs. $[10,85,86]$ used the simplified version of Skalak's equations that represent the well-known four-equation systems for axial FSI. Skalak's work was revisited and analysed in [87].

For the description of pressure waves in pipe systems, two or four-equation models are sufficient [23]. Four-equation models consider the combination of classic theory with the 3-DOF equations. Hence, four fundamental equations, two for the fluid and two for the pipe axial movement, are to be solved. The right-hand side terms of the continuity equations of the 1-DOF and 3-DOF systems must be adapted in order to describe the Poisson coupling in terms of the dependent variables of the four-equation model (i.e., respectively, axial stress of the pipe-wall and fluid pressure). This derivation is explained in Appendix $C$ from which Equations (25) and (27) are obtained:

$$
\begin{gathered}
\frac{\partial V}{\partial t}+\frac{1}{\rho_{f}} \frac{\partial p}{\partial z}=0 \\
\frac{\partial V}{\partial z}+\frac{1}{\rho_{f} a_{h}^{2}} \frac{\partial p}{\partial t}=\frac{2 v}{E} \frac{\partial \sigma_{z}}{\partial t}, \\
\frac{\partial U_{z}}{\partial t}-\frac{1}{\rho_{p}} \frac{\partial \sigma_{z}}{\partial z}=0 \\
\frac{\partial U_{z}}{\partial z}-\frac{1}{\rho_{p} a_{3}^{2}} \frac{\partial \sigma_{z}}{\partial t}=-\frac{r v}{e E} \frac{\partial p}{\partial t} .
\end{gathered}
$$

Equations (24)-(27) can be used to describe pipe systems like the one depicted in Figure 2, where the pipe axial movement is allowed and axial stress waves interact with the inner fluid pressure waves. 


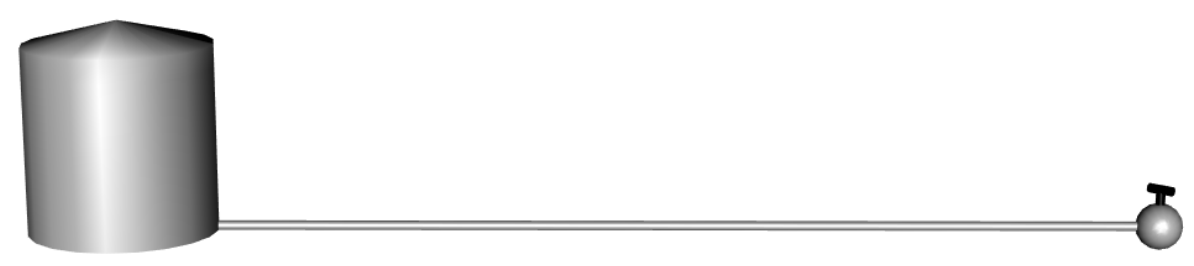

Figure 2. Reservoir-pipe-valve system with a straight pipe which is free to move in the axial direction.

Several numerical methods can be used to solve the above system of equations, either integrating both the fluid and the structure in the same numerical scheme (e.g., MOC-MOC) or by a combination between different schemes (e.g., MOC-FEM).

The four-equation system was solved using MOC procedure for the first time in [10,85]. A series of tests carried out on a vertical pipe line located in a subterranean salt cavern were presented by $[50,85,88]$. Measurements were shown from a water-main bridge in [89-91], and in [10,92] from a loading line between tanks and ships. These measurements were used to develop and validate the four-equation model and to understand FSI mechanisms.

The Method of Characteristics for both the fluid and the structure (i.e., MOC-MOC) was shown to have useful advantages in [93]. This approach was supported by experimental evidence from [94-97], who carried out measurements in which FSI effects were particularly well isolated by means of suspended pipe rigs that were excited by the impact of a solid rod. In combination with their numerical developments, they showed how FSI coupling changes the natural vibrating frequencies, which cannot be predicted by uncoupled approaches.

An FDM scheme in his four-equation model was used in [47] as a simplified version of a six-equation model which was solved by MOC. Fluid and axial stress waves in conduits were modelled by [98] who used a MOC approach taking into account only junction coupling but ignoring Poisson coupling. An FDM approach was used in [49], the implementation was validated by tests on a thin-walled straight pipe for Poisson coupling as well as junction coupling at a closed-free pipe end. An explicit Joukowsky-like expression was presented by [99]. The expression was derived from the four-equation system aiming at estimating maximum pressures during water-hammer with FSI.

A number of research contributions e.g., [7,100-103]) explained how to solve the four-equation system considering Poisson coupling. They presented the characteristic equations after MOC transformation and how to integrate them within the same characteristic grid using time-line interpolations as explained by [104]. The MOC transformation that allows hyperbolic partial differential equation systems to be converted to a set of ordinary differential equations was based on [105]. A FEM scheme was used by [52] for both the fluid and the structure. Time interpolation and wave adjustment methods are compared for MOC-MOC solutions in [106,107]. A hybrid MOC-FEM approach, MOC for the fluid and FEM for the structure, was used in [48], experimental data was used for model verification. An FVM approach was presented in [55] to solve the four-equation model, which was successfully verified using the Delft Hydraulics Benchmark Problem A [51,70]. Both approaches MOC-MOC and MOC-FEM are compared in [51], concluding that for straight pipe problems the MOC procedure is more accurate and efficient. In addition, several approaches were compared in [108] suggesting that MOC methods become difficult to implement for complex pipe geometries and restrictions, for which alternative methods to describe the structure behaviour like FEM or FVM become attractive. A MOC-MOC coupling was used in [109] to simulate a kind of FSI which was experimentally observed in pipe coils by [99,110]. The MOC-MOC approach is also used in [111], who combined pipe-wall viscoelasticity, column separation and unsteady friction with fluid-structure interaction.

The Delft Hydraulics Benchmark Problem A (20 m long, steel pipe, $0.4 \mathrm{~m}$ diameter) is a good test case for the verification of four-equation numerical codes (vi. Figure 3). A theoretical development of an exact solution of the four-equation system by means of a recursion was presented 
in $[12,54,112]$. The drawback of the method is its exponential computational effort for longer simulation periods. Recently, in [56], the computation for the exact solution was upgraded in order to increase computational efficiency and applicability. The analysis suggested to keep the scope of exact solutions to generate test cases and to benchmark solutions for more conventional numerical methods. In addition, in [113], the efficiency was improved by using a hybrid cubic time-line interpolation scheme.

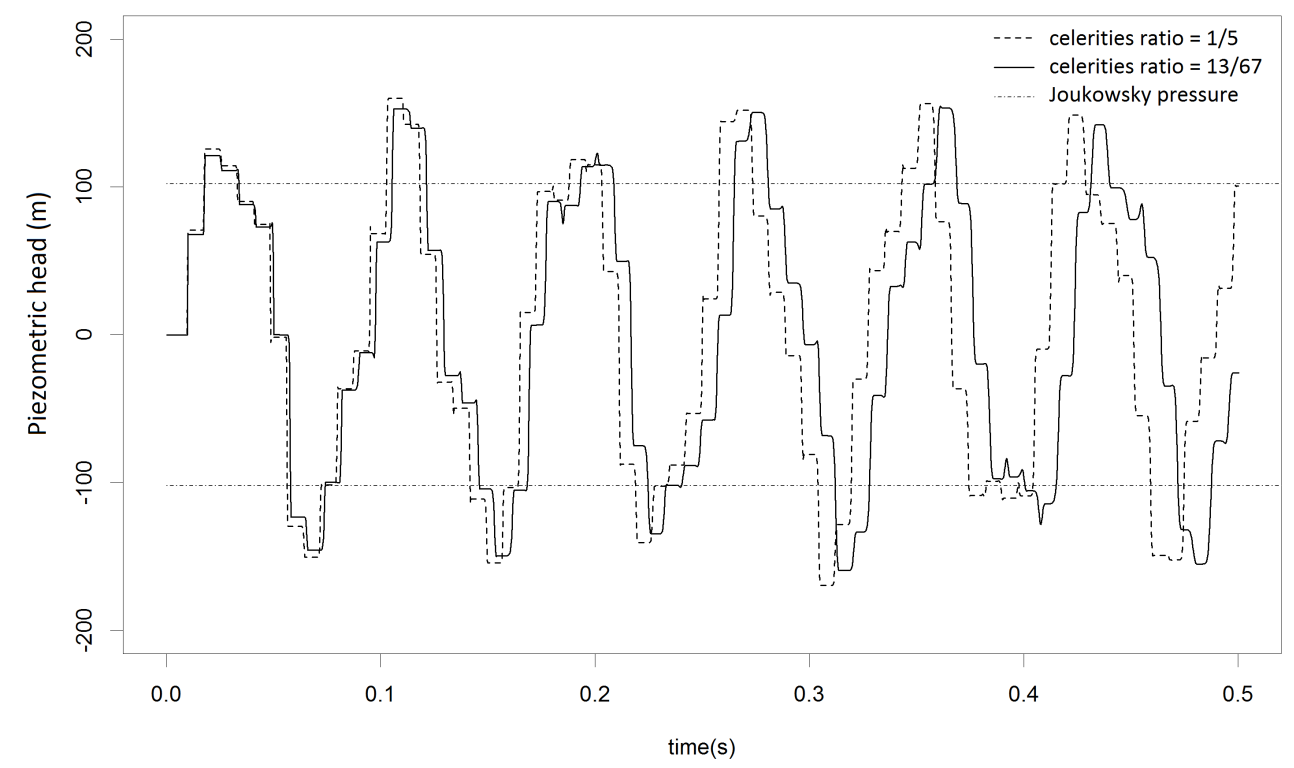

Figure 3. Four-equation code verified by means of the Delft Hydraulics Benchmark Problem A [114].

It is important to highlight that numerical outputs, such as the one presented in v.i. Figure 3, show how FSI phenomena can cause pressure surges higher than the ones expected from classical theory. The Poisson coupling beat, which is a phenomenon that arises from resonance between 1-DOF and 3-DOF, was demonstrated in [115]. Poisson coupling beat was already numerically observed by [8]. So far, there is no experimental evidence about it, as damping mechanisms tend to hide the oscillating resonance between the pipe-wall and the fluid vibrations.

More recently, Ref. [57] numerically observed the Liebau effect in pipe flow using a four-equation model which was adapted to describe the inertia of thrust blocks. The Liebau effect is rather an object of study in the field of physiological flows and is defined as the occurrence of valveless pumping through the application of a periodic force at a place which lies asymmetric with respect to the system configuration [116]. The Liebau effect in pipe flow may be induced by Poisson coupling and should be object of further research (v.i. Figure 4).
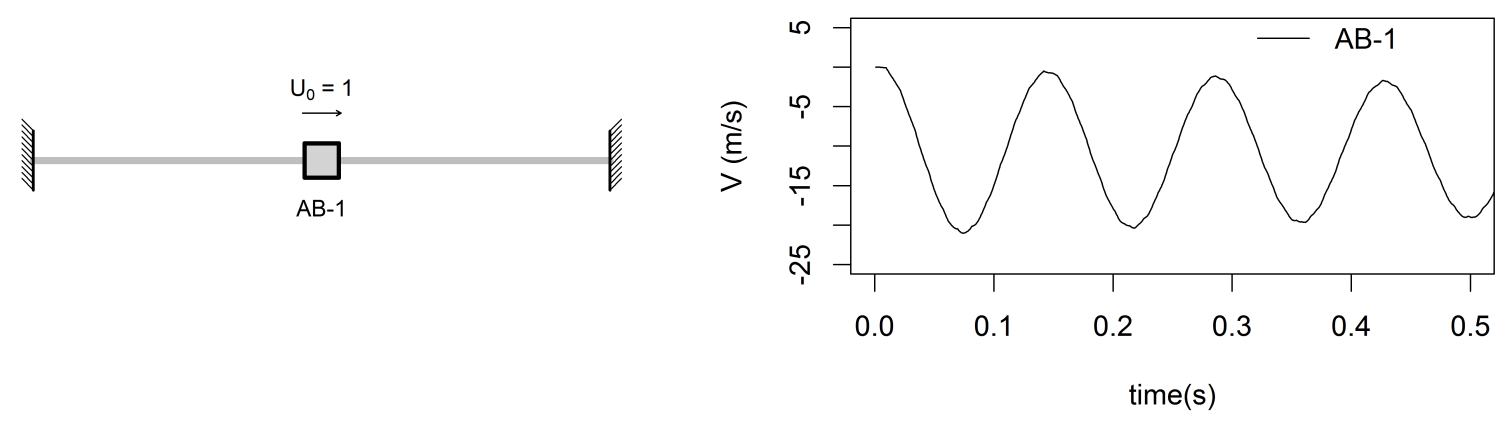

Figure 4. Numerical evidence of Liebau effect depicted in [57]. 


\subsection{Three Degree-of-Freedom Models}

Six-equation models aim at describing the 1,2,3-DOFs. As in the four-equation model, similar numerical schemes can be used for solving the six-equation system. However, the right-hand sides of the three continuity equations are not expressed in differential terms. A first or second-order approximation can be applied for integrating these equations.

The six-equation model by an MOC approach was first proposed and solved by [5]. These authors have compared results from the frequency and time domains and carried out their validation using experimental data collected from a water-filled copper pipe excited by hammering the pipe-end.

With a similar MOC numerical scheme, Ref. [47] solved the equations and compared them to a four-equation model solved by FDM; the effect of Poisson coupling in each case was also analysed. The work of [5] was extended by [58], who proposed an added fluid mass term and solved the equations by a MOC-FEM approach. An MOC-FDM scheme was used by [59] in their numerical analysis, and the effect of initial axial tensional stress was included in their derivation.

From the six-equation system, Ref. [60] derived a four-equation model which included correction terms and factors accounting for the pipe-wall thickness (v.i. Figure 5). The model was validated with exact solutions in the time-domain [12,54]. The authors concluded that, in the low-frequency range, a transient description of the 2-DOF is only important for very thick pipes $(r / e<2)$.

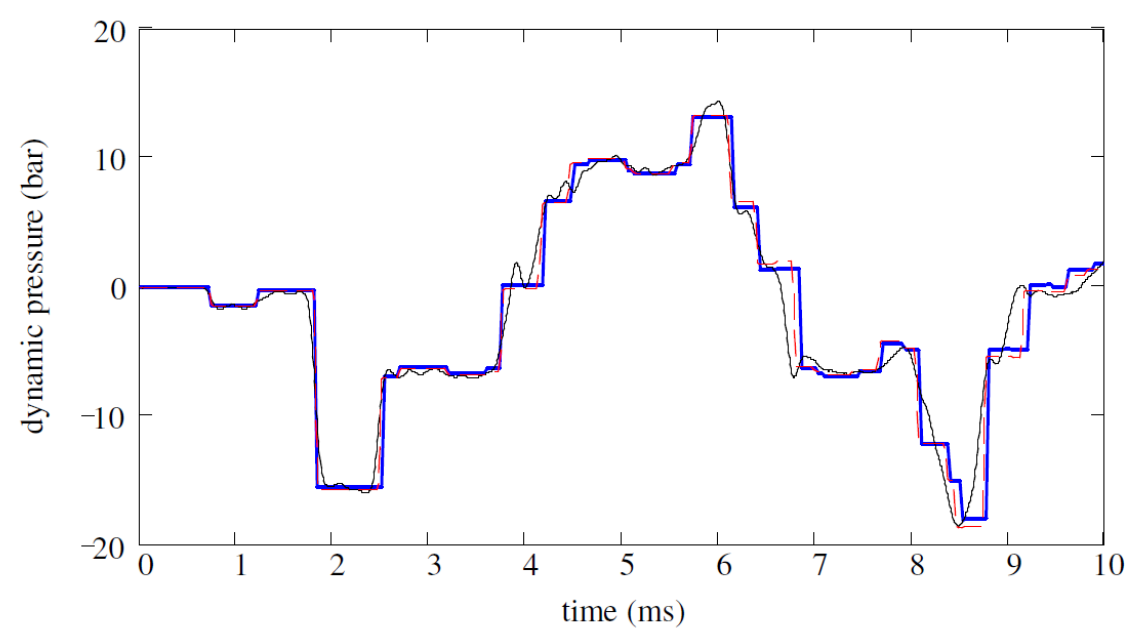

Figure 5. Comparison of transient pressures considering thick-wall theory (thick solid blue line), thin-wall theory (thin broken red line) and experimental data (thin solid black line) [60], $e / r=0.15$.

\subsection{Four Degree-of-Freedom Models}

According to the classification proposed in Section 2.2, eight-equation models solve the system of equations for either 1,3,4,6-DOFs or 1,3,5,7-DOFs. These kind of models are used to describe in-plane axial, torsional and flexural pipe displacements, respectively, in the $\widehat{x z}$ or $\widehat{y z}$ planes. Radial deformation is nested in the celerity of the 1-DOF as in the classic water-hammer theory. Poisson coupling may be included such that the system of equations to be solved becomes composed of Equations (24)-(27) (i.e., the four-equation model) together with Equations (7), (8), (11) and (12) or Equations (9), (10), (13) and (14). The 4,5,6,7-DOFs are only coupled by means of junction coupling.

Pipe systems like the one depicted in Figure 6 can be described by 4-DOF models. In this pipe scheme, a water-hammer wave generated by the valve manoeuvre would induce not only transient pressures but axial stress, shear stress and bending waves in the pipe wall, hence exciting the 1,3,4,6-DOFs. 


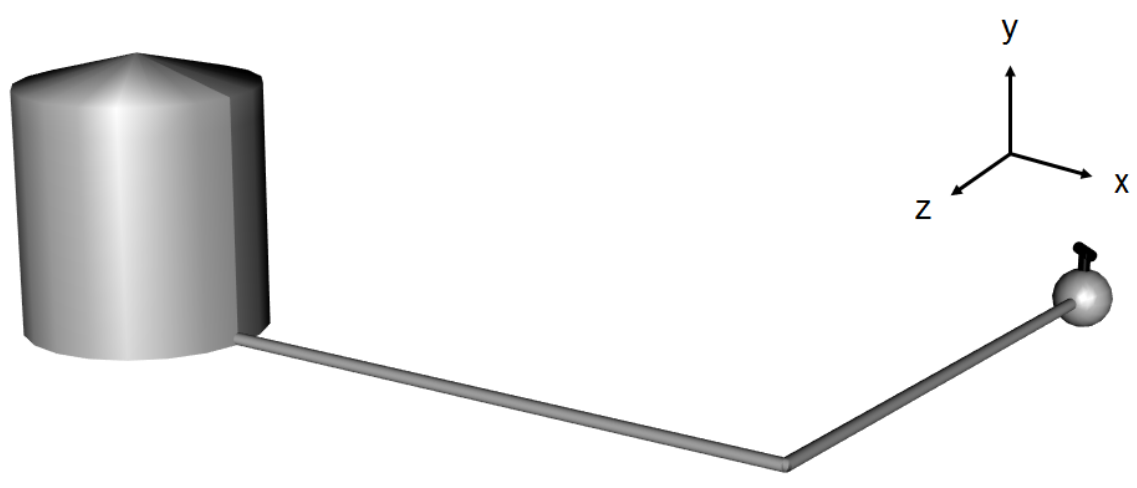

Figure 6. Reservoir-pipe-valve system with a $90^{\circ}$ elbow in the middle section of the pipe.

The eight-equation model for curved pipes for 1,3,4,6-DOFs was presented in [6], the transient fluid flow was coupled with the axial, shear and bending transient waves of the pipe-wall. The same equations using MOC were solved by [64], who validated the results against new experimental data. Radial inertia was included by [9] who solved a nine-equation model. A MOC-MOC scheme in combination with cavitation was used in [65-67], the cavitation effect was modelled by means of a lumped parameter model. An FVM method was used by [68] to solve the eight-equation model, which was tested for different set-ups (v.i. Figure 7). In this analysis [55], it was pointed out that a two-phase flow model is needed for simulations of more universal FSI problems occurring in pipelines.

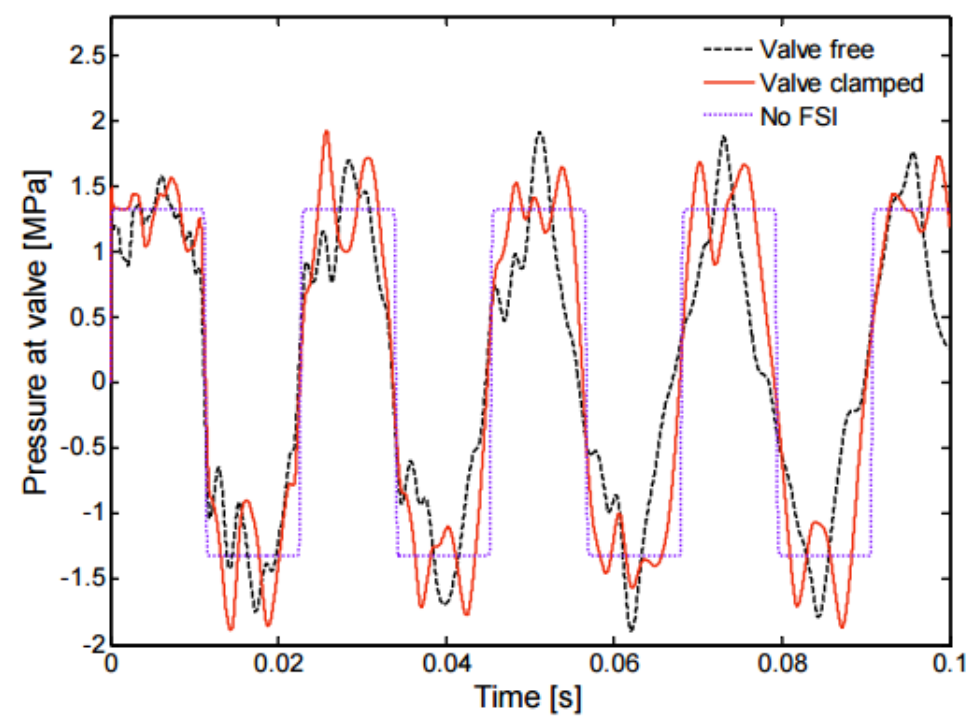

Figure 7. Numerical output from [68] considering a free moving valve (black dashed line), anchored (red solid line) and compared with the classic water-hammer model output (purple doted line).

A compilation of sixteen experiments dedicated to systems with a single elbow (L-pipes) was presented in [117], eight experiments focused on the frequency-domain approach and eight on the time-domain. The experiments based on the time-domain approach are presented in Table 2. 
Table 2. Main time-domain experiments carried out for single-elbow pipes.

\begin{tabular}{clc}
\hline Reference & Experimental Setup & Transient Test \\
\hline [118] & $\begin{array}{l}45^{\circ}-180^{\circ}, \text { hor. mitre, } \\
\text { hor. curved bends } \\
0.85<R_{c} / D<5.0, \\
\text { rigid }(2 \text { jacks })\end{array}$ & $\begin{array}{c}\text { valve closure: } 2-5 \mathrm{~ms} \\
\text { initial flow vel.: } 0.6-2.4 \mathrm{~m} / \mathrm{s}\end{array}$ \\
\hline$[62]$ & $\begin{array}{l}30^{\circ}-150^{\circ}, \text { hor. mitre, } \\
\text { rigid and free }\end{array}$ & $\begin{array}{c}\text { valve closure: } 2 \mathrm{~ms} \\
\text { initial flow vel.: } 2-3 \mathrm{~m} / \mathrm{s}\end{array}$ \\
\hline$[63]$ & $\begin{array}{l}\text { hor. } 114.3 \mathrm{~mm}, \\
D=70.6 \mathrm{~mm},\end{array}$ & $\begin{array}{c}\text { gun: } 150 \text { bar } \\
\text { pulse } 3\end{array}$ \\
\hline$[64]$ & $R_{c} / D=1.6$, rigid & pellet impact $0.2 \mathrm{~m} / \mathrm{s}$ \\
\hline$[119]$ & hor. $R_{c} / D=0.8$ & $\begin{array}{c}\text { valve closure: } 4 \mathrm{~ms} \\
\text { initial flow vel.: } 1.2 \mathrm{~m} / \mathrm{s}\end{array}$ \\
{$[120]$} & hor. $0.88 \mathrm{~kg}$ & rod impact $0.15 \mathrm{~m} / \mathrm{s}$ \\
{$[66]$} & hor. $R_{c} / D=2.2$ & impact hammer pulse $1-2 \mathrm{~ms}$ \\
\hline$[121]$ & vert. elbow $R_{c} / D=1.5$ & $\begin{array}{l}\text { valve opening: } 20-200 \mathrm{~ms} \\
\text { initial flow vel.: } 2-17 \mathrm{~m} / \mathrm{s}\end{array}$ \\
\hline$[122]$
\end{tabular}

From an experimental standpoint, Ref. [118] tried to prove that a pressure wave reflects partially when passing through a rigidly supported elbow. This work generated in-depth discussion pointing out the importance of considering FSI even for rigid supports assuming that the movement of anchorages is nearly impossible to avoid. This idea was supported by [62] who stated that pipelines are never anchored sufficiently to eliminate motion due to a water-hammer surge. A complete pipe rig was used in [63]; nonetheless, they experienced difficulties in getting rid of undesired FSI effects, emphasizing the importance of properly testing experimental setups preventing such phenomena. Finally, Refs. [120] verified that there is no pressure wave reflection from an immobile elbow but that there is due to the elbow movement. These findings were confirmed once more in [123].

A pipe system with multiple elbows, bends and junctions can be described by eight-equation models if these are located in the very same plane. This is the case for the experiment carried out in the University of Guanajuato, Mexico, in collaboration with the University of Lisbon, Portugal. Data from a pipe rig assembled by concentric elbows of $90^{\circ}$ was collected by $[40,124]$. The apparatus was equipped with pressure transducers and accelerometers. Water-hammer events were generated by a downstream valve manoeuvre. The aim of the experimental data collection was the validation of a numerical model which coupled CFD software for the fluid with FEM software for the structure. The model was compared also with a modified MOC approach which included damping coefficients to account for structural damping. The work highlighted the importance of integrated analyses including the description of both fluid and structure behaviours.

\subsection{Seven Degree-of-Freedom Models}

The fourteen-equation model includes all the degrees-of-freedom presented in Section 2 except the 2-DOF corresponding to the radial inertia of the pipe-wall, which is nested in the celerity of the 1-DOF like in the classic water-hammer theory. Hence, the system to be solved is composed of Equations (24)-(27) (i.e., the four-equation model) together with Equations (7)-(16). Pipe systems like the one depicted in Figure 8 can be described by 7-DOF models, where all the related DOFs would be excited by a water-hammer wave generated at the downstream valve. 


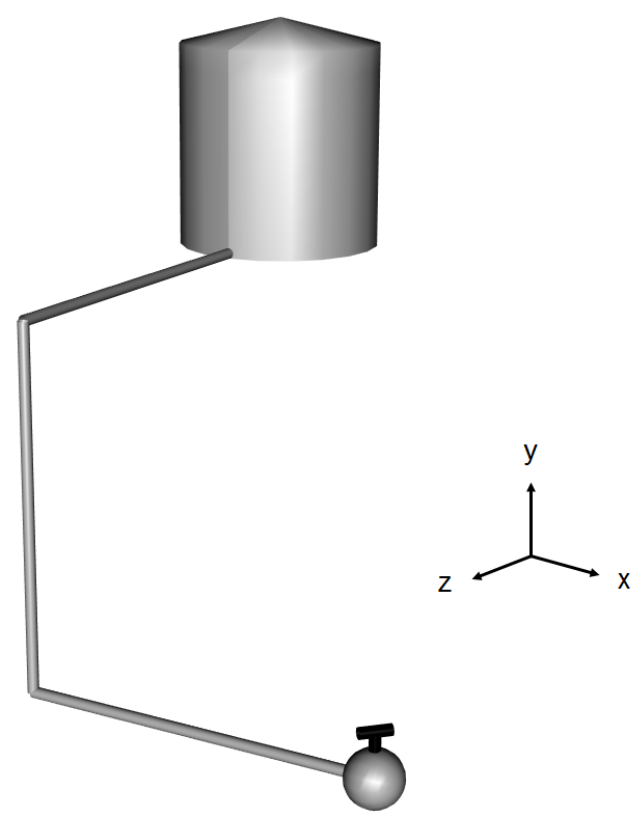

Figure 8. Reservoir-pipe-valve system with two out-of-plane $90^{\circ}$ elbows.

The fourteen-equation model in the time-domain was introduced by [4]. The model was finally implemented by $[7,8,120]$ with MOC approach, both in the fluid and in the structure. Experimental fluid pressure and structural velocity measurements from [7], corresponding to a similar set-up as the one depicted in Figure 8, are shown in Figure 9. A good fitting with measurements was obtained, but the analysis concluded that further model developments were necessary. The work was extended by [125] using an experimental set-up consisting of a copper pipe containing a U-bend free to move in an in-plane fashion. This method was used also by [126], who simulated an accident.

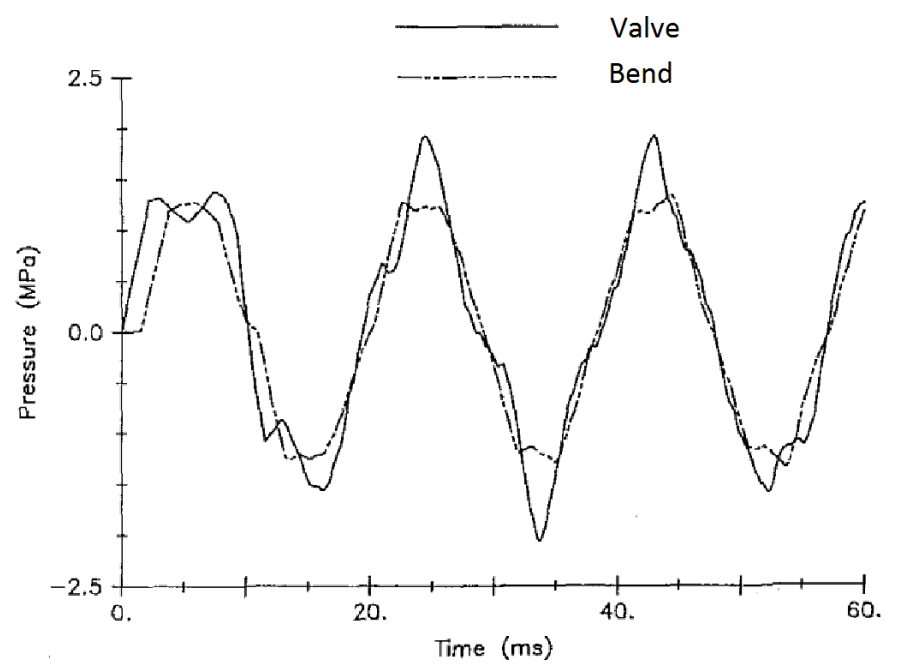

Figure 9. Experimental pressure measurements next to the downstream valve and at a bend [7].

Experiments were carried out in a PVC pipe containing a U-shaped section at the laboratory of Delft Hydraulics, the Netherlands, in [69]. The author concluded that classic water-hammer theory was not accurate enough to describe the behaviour of the pipe-rig and, consequently, the FLUSTRIN project was launched. A complex and large-scale apparatus (Figure 10) held by suspension wires and specially designed for FSI tests was assembled at Delft Hydraulics laboratory and used for the development 
and verification of the FLUSTRIN code, which is based on a MOC-FEM approach [70,71]. In this framework, Refs. $[127,128]$ carried out a series of numerical benchmark tests. Coupled and uncoupled Poisson effect solutions were compared for the Delft Hydraulics Benchmark Problem F [129], which is a good approach for verifying fourteen-equation model implementations (v.i. Figure 11). Experimental measurements were used in this comparison and a guideline was provided suggesting when FSI is important. The same computer code was used by $[51,72,74]$ with similar purposes of comparing with other modelling assumptions and using experimental tests for validation. Ref. [74] suggested that, for four-equation modelling, an MOC-MOC approach is more convenient, while, for higher degrees-of-freedom, an MOC-FEM scheme is preferable as higher grid resolution is required. A similar MOC-FEM code with differences in the implementation of the Poisson coupling mechanism was presented in [73]. The MOC-FEM approach was used for junction coupling assessment of unrestrained pumps and branches in [130]. In addition, an MOC-FEM approach was used in [131] in which the effect of pipe-wall viscoelasticity was added. A model using a velocity based FEM formulation was developed by [132], the implementation was validated with benchmark problems. Time-domain solutions can be also obtained from frequency-domain analyses; however, Ref. [133] concluded that the time-domain solutions derived from frequency-domain results are difficult and impractical.

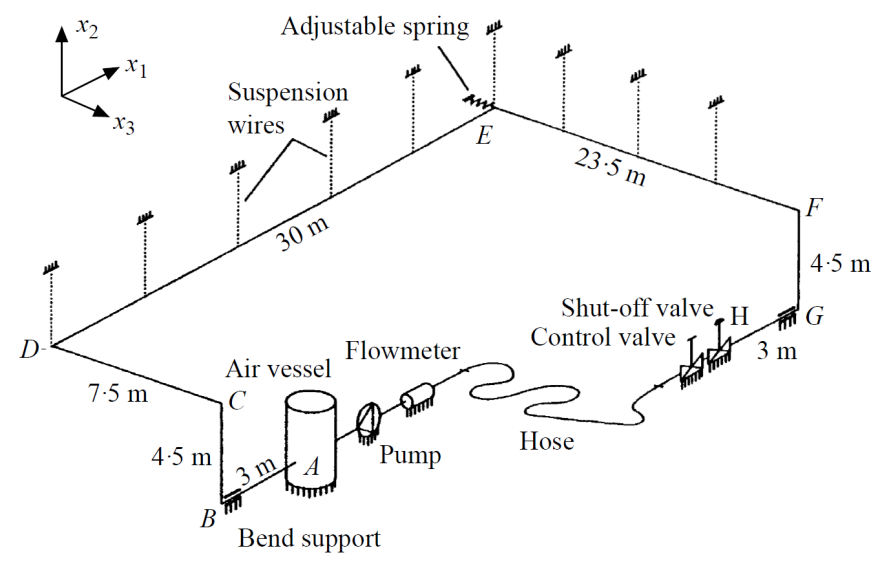

Figure 10. FSI experimental set-up at Delft Hydraulics [127].

(a)

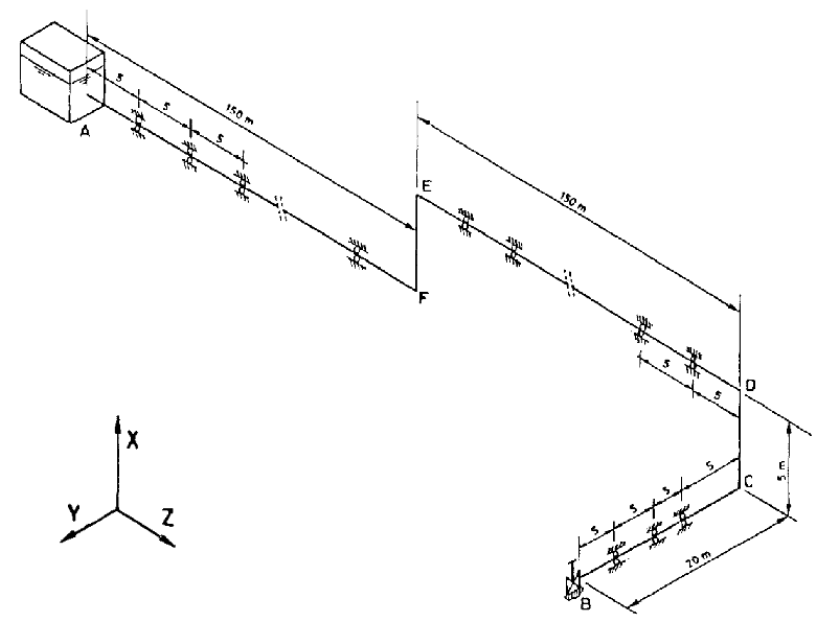

(b)

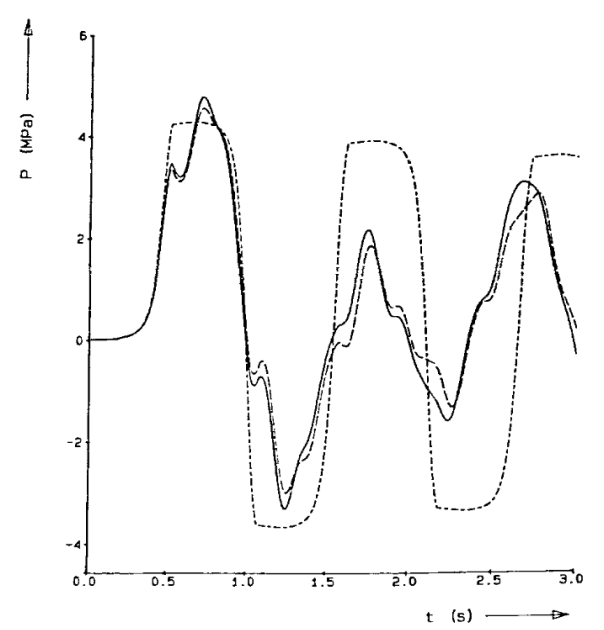

Figure 11. Set-up of the Delft Hydraulics Benchmark Problem F (a); and numerical output (b) for: Poisson and junction coupling (solid line), only junction coupling (dashed line) and for classic water-hammer model (dash-dotted line) [70]. 


\subsection{Other FSI Mechanisms}

In curved pipes of non-circular cross-section, an additional coupling mechanism, called Bourdon coupling, affects the pipe behaviour. This mechanism consists of the change of ovality of the pipe cross-section in function of the internal pressure loading. Fluid-Structure Interaction was analysed, respectively, in straight and curved pipes in $[134,135]$. The Bourdon tube deformation mechanism is explained in $[136,137]$ and a methodology based on the Boltzmann superposition principle to describe stress-strain states is presented. Bourdon phenomena by means of an FEM approach was studied by $[138,139]$. The Bourdon effect was first dynamically coupled with the fluid response in [140]. The work was extended in [141,142], where experimental measurements were used for validation of the numerical output in the frequency domain.Experimental evidence of Bourdon coupling was given also by $[97,143]$.

Other FSI mechanisms not that common in regular engineering practices are the buckling and flutter induced by centrifugal and Coriolis forces. Authors that have contributed to this matter are: [144-147]. Experimental research focused on describing the buckling and flutter effects in pipe systems was conducted in [145,148]. An encyclopaedic treatment of the subject is given in [149].

\section{Engineering Applications}

\subsection{FSI Consideration in Codes and Standards}

Table 3 refers to the Codes and Standards belonging to those engineering fields that frequently require water-hammer analyses. Other Standards and Guidelines have been reviewed by [150]. However, none of the Standards directly consider any kind of FSI coupling. Several industrial cases of FSI generated by internal flows are analysed in [151]. The paper highlights the complexity of FSI problems and the need for guidelines and rules in international Codes and Standards.

Table 3. Codes and Standards in industries where water-hammer analyses are frequent.

\begin{tabular}{ccc}
\hline Industry & Application & International Standards \\
\hline \multirow{2}{*}{ Hydropower energy } & penstocks & ASME-B31.3 \\
& & DIN-19704-1 \\
& & ASCE MOP 79 \\
Nuclear/Thermal energy & \multirow{2}{*}{ cooling systems } & ASME-BPV \\
& & NS-G-1.9 \\
\hline \multirow{2}{*}{ Oil/Gas transportation } & \multirow{2}{*}{ oil/gas mains } & ASME-B31.2 \\
& & ASME-B31.4 \\
& \multirow{2}{*}{ water pipes } & ISO-13628 \\
\hline \multirow{2}{*}{ Wastribution } & & PDI-WSH 201 \\
\hline \multirow{2}{*}{ Aerospace } & \multirow{2}{*}{ fuel pipes } & ISO/FDIS-8575 \\
& & NASA-STD-8719 \\
\hline
\end{tabular}

\subsection{Anchor and Support Forces}

Fluid-Structure Interaction and especially the behaviour of pipe supports have a direct applicability in above-ground or non-buried pipe systems, such as hydropower systems, long oil and gas pipes, cooling systems of nuclear, thermal plants or any fluid distribution system in industrial compounds. However, only a few authors investigated anchor and support behaviour in the context of water-hammer theory. Frequently, studies are based on qualitative discussions focused on post-accident analyses and mitigation measures case-by-case oriented. An example is [152] where recommendations for design criteria, operating rules and post-accident analyses were given. 
In addition, Refs. [153-155] presented qualitative discussions of the performance of different industrial piping systems, giving insights into pipe support behaviour. The latter highlighted the case-by-case dependency of Fluid-Structure Interaction and the high computational demand of including anchor analyses, stating that the scope of such studies should be justifiable only for very critical systems, such as in nuclear power plants.

Data from a firewater facility pipeline was collected in [10], who carried out numerical analyses by means of MOC. The effect of support rigidity of pipe systems was studied by [156] and discussed for what rigidity of the supports FSI becomes a dominant effect. In their analysis, they applied both classic water-hammer theory and a MOC-FEM approach by means of the FLUSTRIN code [71,127]. The simulated facility corresponded to the one from Delft Hydraulics laboratory.

A study of the effect of a pipe-rack considering the dry friction occurring between the rack and the pipe-wall was carried out in [157]. Recommendations were given in order to assess when dry friction must be considered. Following this line, Refs. $[57,99,158]$ carried out experimental and numerical work based on a straight copper pipe which allowed a broad variety of anchoring configurations. In [57], a robust and accurate MOC-MOC code to simulate anchoring blocks taking into account their inertia and dry friction was presented. The blocks were nested in the numerical scheme as internal conditions and junction coupling was considered. Figure 12 depicts the model output vs. experimental measurements for different anchoring set-ups.

(a)

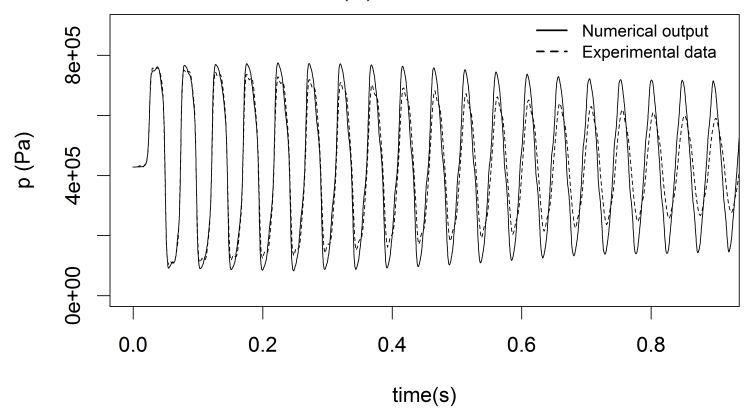

(c)

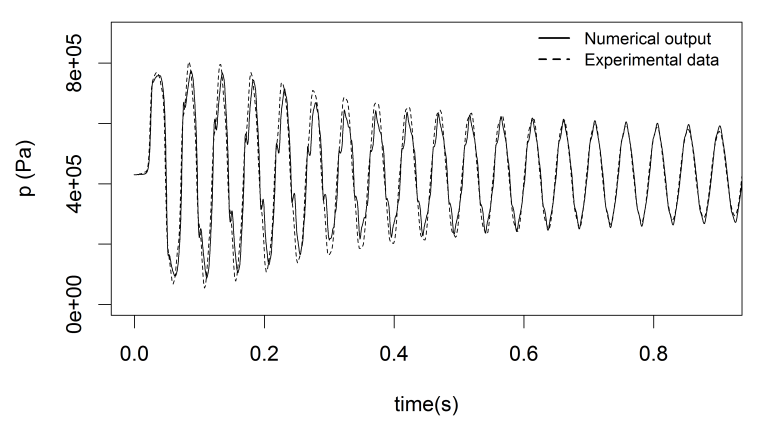

(b)

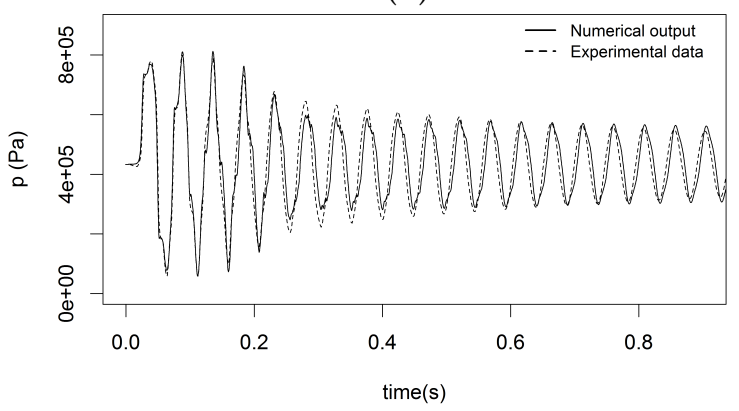

a)

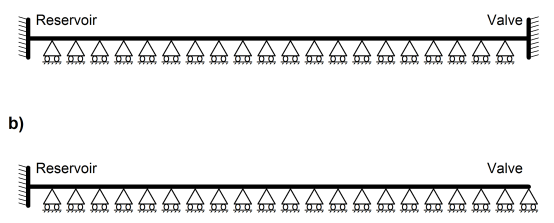

c)

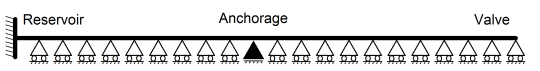

Figure 12. Validation of the numerical model developed in [57] for: anchored pipe ends (a); released downstream end (b); and released downstream end but anchored midstream (c).

Different anchoring conditions were assessed in [124] using CFD software, which was validated by means of experimental data. The analysis pointed out the need for CFD simulations for the proper description of pipe support behaviour. In [159], the aim was the simulation of hydraulic transients in a straight pipe anchored with axial supports using an MOC-FEM approach. Both pipe-wall and supports had a viscoelastic behaviour. The study concluded that the viscoelastic supports significantly reduce displacements and stresses in the pipe and eliminate the high-frequency fluctuations produced due to FSI. A multi-span pipe system, with rigid constraints in the middle section, was analysed in the 
frequency-domain by $[160,161]$ using the transfer matrix method, concluding that the middle rigid constraints have a much larger effect than the Poisson coupling. These types of multi-span pipes with middle rigid constraints set-ups are common in engineering practices and, so far, only a limited number of investigations has been carried out addressing this issue, especially in time-domain analyses.

\subsection{Vibration Damping and Noise Reduction}

Pipe vibration may induce audible noise and FSI analyses are required for the assessment of such noise. The vibrating modes that produce sound were investigated by [162]. Experimental analyses were carried out by $[163,164]$, who developed a technique to reduce noise generation by the specific positioning of pipe clamps. Ref. [165] suggested that, for the full description of sound generation in pipe-systems, seven degrees-of-freedom are required. This statement was verified in [166]. A pump-induced fluid-borne noise investigation is carried out by [167] by means of a distributed-parameter transfer-matrix model in the frequency-domain. It was claimed that the method could be used as well for structure-born noise as long as Fluid-Structure Interaction was taken into account.

Experimental water-hammer tests on a steel pipe containing a short segment of ABS were presented in [168]. MOC was successfully used to reproduce the experiments and they concluded that the vibration could be adapted and modified in the functioning of the segment material and geometry. A similar conclusion was reached by [169], who used an aluminium pipe set-up with a short segment of PVC. The analysis was carried out in the frequency-domain. Related with the previous subsection, Ref. [170] proposed a methodology to reduce vibrations by the installation of intermediate supports.

\subsection{Earthquake Engineering}

Water-hammer waves can be produced by earthquake excitation on a pipe system. Fluid-Structure Interaction or soil-pipe interaction may be one of the potential damaging factors during earthquakes, especially for relatively low pressure and large diameter pipelines [171]. The Fukushima Daiichi nuclear disaster in Japan is a prominent example of this [172,173]. Some authors have studied these kinds of transients coupled with FSI. A Z-shaped piping system subjected to a one-directional seismic excitation was analysed by [174]. A numerical analysis of a 3D pipe system was carried out in [175]. It was found that assuming the piping to be rigid produced an upper-bound estimate of pressure, but assuming the liquid to be incompressible resulted in underestimating the displacement of the piping. Coupled and uncoupled analyses applied to a single straight pipe were compared in [73], who also concluded that coupled analyses accurately predicted lower wave amplitudes.

\subsection{Aerospace Engineering}

Strong fluid transients occur in the filling up process of propulsion feedlines of satellites and launchers. In the experimental works of $[30,61,63,176]$, different configurations of rocket fuel-filled pipe rigs were tested. An overview of the main concerns experienced in the aerospace community with respect to fluid-hammer was reported by [177]. The study mentions the need for detailed investigation of Fluid-Structure Interaction in combination with thermal heat transfer during fluid-hammer waves in satellites or launchers. In addition, the importance of FSI in the filling of pipelines during the start up of the propulsion systems of spacecrafts was highlighted by [178], claiming that more experimental research should be focused on this line.

\subsection{Biomechanics}

The disciplines of hydraulic transients and physiological flows share a good basis of the classic water-hammer theory as long as the assumptions of liquids with relatively low compressibility contained in thin-walled elastic cylindrical tubes are considered. Studies such as [20,179-185] focused on adapting classic water-hammer to the main factors that affect physiological flows. For instance, in [181], the Korteweg formula for wave celerity computation was reviewed in order to include pipe 
cross-section ovality effects. The study concluded that, even for a low ovality of the pipe cross-section, there may be significant reductions of the wave velocity due to bending-induced changes in the tube cross-section. The analysis carried out by [181] serves also in the field of hydraulic transients for pipe bends and coils where the pipe cross-section becomes elliptic.

Nowadays, computational-fluid-dynamics (CFD) tools are used to model the complexity of haemodynamics. Not just the pipe-wall viscoelasticity and the elliptic pipe cross-section, but the inner fluid defies as well classic water-hammer theory assumptions as blood is a non-Newtonian fluid, presenting shear-thinning, viscoelasticity and thixotropy. A review of modern modelling approaches for haemodynamical flows was presented in [186]. A comparison of different physiological assumptions is carried out by means of an FEM-FEM approach in [187]. Newtonian and non-Newtonian assumptions are considered with Fluid-Structure Interaction, highlighting their differences and the importance of good modelling criteria. More specific to blood flow diseases diagnoses, Ref. [188] also used CFD tools, including FSI, for modelling a vein blockage induced by a deep venous thrombosis and the occurrence of reverse flow in human veins.

\subsection{Accidents and Post-Accident Analyses}

FSI may generate overpressures higher than that predicted by Joukowsky's formula and not only caused by water-hammer waves, but also by turbulence-induced vibrations, cavitation-induced vibrations or vortex shedding with lock-in. These phenomena are poorly understood [151] and are rarely taken explicitly into consideration in engineering designs, leading to accidents and service disruptions of important infrastructure with large social relevance e.g., industrial compounds, water and wastewater treatment plants, thermal plants, nuclear power plants, hydropower plants).

A number of the most serious accidents due to water-hammer in pressure conduits until WWII were reviewed in [189]. Many of the failures described were related to vibration, resonance and auto-oscillation [190]. Table 4 summarizes a selection of accidents caused by strong hydraulic transients found in the literature, noting that the majority of incidents and accidents remains 'unpublished'.

Normally, accidents in hydraulic facilities are associated not only to a single phenomenon but to a sequence of events that make the system collapse. Although not all the accidents listed in Table 4 were caused directly by FSI, in many cases, FSI is involved in this sequence of events and its understanding is crucial in post-accident analyses, such as reported in [126,152,191,192]. Water-hammer related accidents in nuclear power plants was investigated by [193], where water-hammer waves compress flammable gasses to their autoignition temperatures in piping systems. In this paper, several examples of incidents and accidents are analysed enhancing the understanding of nuclear power plant explosions.

Table 4. Selection of historical accidents in pressurized pipe systems mentioned in the literature.

\begin{tabular}{|c|c|c|}
\hline Location & Facility & Description and Citations \\
\hline Oigawa, Japan & Penstock & $\begin{array}{l}\text { A water-hammer wave, caused by a fast valve-closure, split the } \\
\text { penstock open and produced the pipe collapse upstream [194]. }\end{array}$ \\
\hline Big Creek, U.S.A. & Penstock & Burst turbine inlet valve caused by a fast closure [195]. \\
\hline Azambuja, Portugal & Pump station & $\begin{array}{l}\text { Collapse of water column separation causing the burst of the } \\
\text { pump casing [80]. }\end{array}$ \\
\hline Lütschinen, Switzerland & Penstock & $\begin{array}{l}\text { Penstock failure during draining due to the buckling } \\
\text { produced by a frozen vent at the upstream end [80]. }\end{array}$ \\
\hline Arequipa, Peru & Penstock & $\begin{array}{l}\text { The clogging of the control system of a valve resulted in } \\
\text { buckling and the failure of the welding seams of } \\
\text { the penstock due to fatigue [80]. }\end{array}$ \\
\hline
\end{tabular}


Table 4. Cont.

\begin{tabular}{ccl}
\hline Location & Facility & Description and Citations \\
\hline $\begin{array}{c}\text { Ok, } \\
\text { Papua New Guinea }\end{array}$ & Power house & $\begin{array}{l}\text { The draft tube access doors were damaged and } \\
\text { the power house flooded due to column } \\
\text { separation in the system [80]. }\end{array}$ \\
\hline Lisbon, Portugal & Water main & $\begin{array}{l}\text { Rupture of concrete support blocks during the slow } \\
\text { closure of an isolation valve installed } \\
\text { in a large suction pipe [192,196]. }\end{array}$ \\
\hline New York, U.S.A. & Steam pipe & $\begin{array}{l}\text { Condensation-induced water-hammer caused the } \\
\text { rupture of the steam pipe [197]. }\end{array}$ \\
\hline Lapino, Poland & Penstock & $\begin{array}{l}\text { Burst of the penstock caused by a rapid } \\
\text { cut-off and low quality of the facility [198]. }\end{array}$ \\
\hline Nhernobyl, Ukraine & Nuclear reactor & $\begin{array}{l}\text { Fuel pin failure, fuel-coolant interaction and } \\
\text { Fluid-Structure Interaction were involved } \\
\text { in the failure of the nuclear reactor [191]. }\end{array}$ \\
\hline New York, U.S.A & Nuclear reactor & $\begin{array}{l}\text { Circumferential weld failure in one of the } \\
\text { feedwater lines due to a steam } \\
\text { generator water-hammer [199]. }\end{array}$ \\
\hline
\end{tabular}

\section{Conclusions}

Not considering pipe-wall movement during water-hammer events is going against the essence of water-hammer research. As shown in Appendix B, the classic water-hammer equations assume a quasi-steady circumferential deformation of the pipe-wall. The information of this quasi-steady behaviour of the piping structure affecting the pressure wave is, in the classic approach, enclosed in the water-hammer wave celerity, which may be eventually affected, as well, if other pipe degree-of-freedoms are considered. Jumping from this quasi-steady assumption of the pipe structure to an unsteady one is what makes the trade between the fluid and the structure dynamic; Fluid-Structure Interaction arises and the classic water-hammer theory becomes invalid. Even in very well controlled conditions of hydraulic laboratories, undesired FSI phenomena are frequent. An important challenge of experimental research in FSI is the setting up of the right design to fit the research purpose. Validation of the test rig itself is, therefore, crucial.

Fluid-Structure Interaction is a case-dependent problem; there is no general solution or numerical model capable of describing and simulating any pipe setup. The technical challenge in the scope of 1D FSI is not resolving the fundamental equations, but assuming the appropriate coupling between the different pipe degrees-of-freedom without ending up in expensive computations. This case-dependency feature and the lack of user-friendly tools is what makes FSI problems difficult to tackle in engineering practice. Additionally, there is a general consuetudinary thinking that classical approaches remain on the conservative side. Though, in this review, it has been shown how authors demonstrated, both numerically and experimentally, that FSI may generate overpressures higher than ones estimated by the classical solutions. Moreover, there is no engineering code or standard specifying when FSI has to be considered. All of these factors pinpoint that the physics of FSI phenomena are not fully understood in common engineering practices and this involves the potential risk of underrated designs.

Author Contributions: D.F. investigated the resources and prepared the original draft, which was supervised, reviewed and edited by D.I.C.C., P.A.M. and A.J.S.

Funding: This research was funded by the Portuguese Foundation for Science and Technology (Fundação para a Ciência e a Tecnologia) grant number PTDC/ECM/112868/2009 "Friction and mechanical energy dissipation in pressurized transient flows: conceptual and experimental analysis", the PhD grant SFRH/BD/51932/2012 also issued by FCT under IST-EPFL joint PhD initiative and by the Swiss Competence Center for Energy and Research-Supply of Electricity (SCCER-SoE). 
Acknowledgments: The authors thank Arris S. Tijsseling (Eindhoven University of Technology, The Netherlands) for his valuable suggestions.

Conflicts of Interest: The authors declare no conflict of interest.

\section{Abbreviations}

The following abbreviations are used in this manuscript:

$A_{f} \quad$ fluid cross-sectional area $\left(\mathrm{m}^{2}\right)$

$a_{f} \quad$ pressure wave speed $\left(\mathrm{ms}^{-1}\right)$

$A_{p} \quad$ pipe-wall cross-sectional area $\left(\mathrm{m}^{2}\right)$

$a_{n} \quad$ acoustic speed of the $i$-DOF $\left(\mathrm{ms}^{-1}\right)$

$D$ pipe inner diameter $(\mathrm{m})$

$E \quad$ pipe-wall Young's modulus $(\mathrm{Pa})$

e pipe-wall thickness (m)

$G$ shear modulus $(\mathrm{Pa})$

I second moment of area $\left(\mathrm{m}^{4}\right)$

$J$ polar second moment of area $\left(\mathrm{m}^{4}\right)$

$K \quad$ bulk modulus of compressibility (Pa)

$L \quad$ pipe length (m)

$M$ moment ( $\mathrm{N} \mathrm{m})$

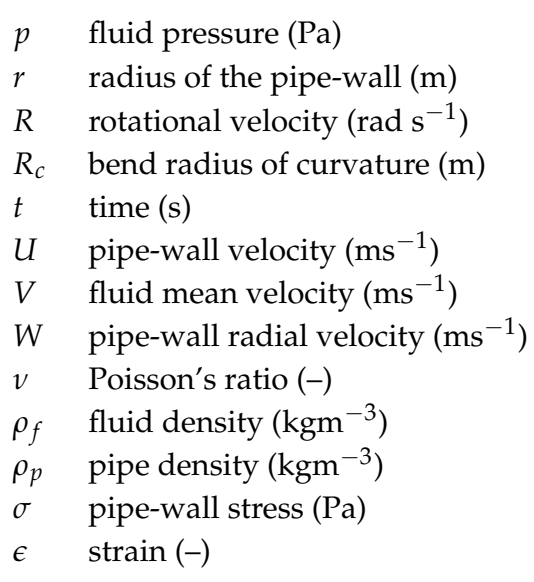

Appendix A. Summary Tables of Experimental and Numerical Research

Table A1 summarizes some of the most relevant contributions that enabled the theoretical development, implementation and application of numerical models using adapted versions of the fundamental equations presented in Section 2.3.

Table A1. Summary table of relevant numerical research in 1D FSI.

\begin{tabular}{ccc}
\hline DOF & Method & References \\
\hline $1 \& 3$ & MOC-MOC & {$[51,57,93,98,106,107,109,158,200]$.} \\
\hline $1 \& 3$ & FDM-FDM & {$[47,49]$.} \\
\hline $1 \& 3$ & FEM-FEM & {$[52]$.} \\
\hline $1 \& 3$ & MOC-FEM & {$[48,51]$.} \\
\hline $1 \& 3$ & FVM-FVM & {$[55]$.} \\
\hline $1 \& 3$ & Analytical solution & {$[12,54,56,112]$.} \\
\hline $1,2 \& 3$ & MOC-MOC & {$[5,47]$.} \\
\hline $1,2 \& 3$ & MOC-FEM & {$[58]$.} \\
\hline $1,2 \& 3$ & MOC-FDM & {$[59]$.} \\
\hline $1,3 \& 4,6$ or 5,7 & MOC-MOC & {$[64-67]$.} \\
\hline $1,3 \& 4,6$ or 5,7 & FVM-FVM & {$[68]$.} \\
\hline $1,3,4,5,6,7 \& 8$ & MOC-MOC & {$[7,8,126]$.} \\
\hline $1,3,4,5,6,7 \& 8$ & MOC-FEM & {$[51,70-74]$.} \\
\hline
\end{tabular}

In Table A2, a summary of the main experimental research work related with FSI in pipe transient flow is depicted, organized by research institutes, authors and dates. Details of these research contributions are provided in the following subsections. 
Table A2. Summary table of relevant experimental work in 1D FSI.

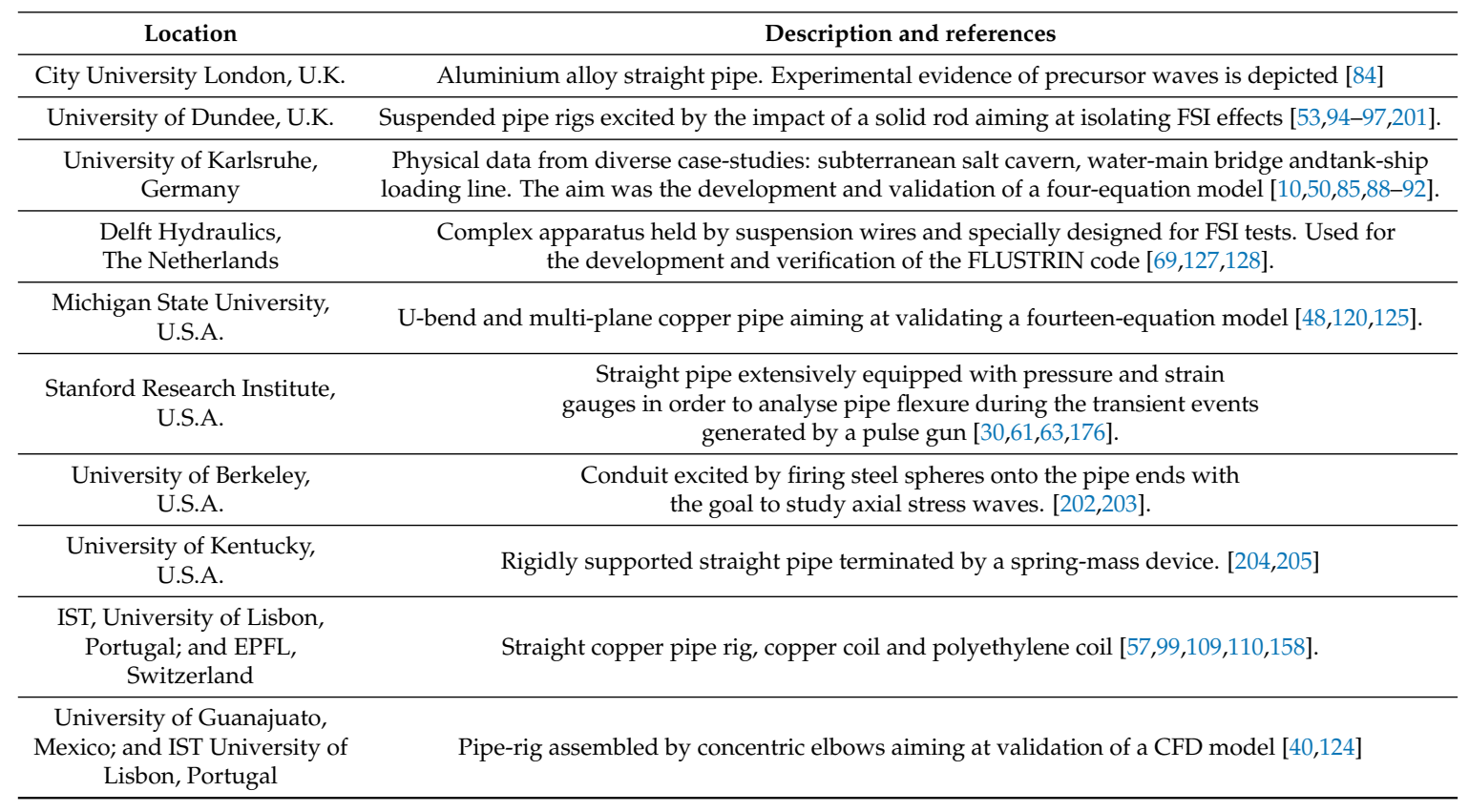

\section{Appendix B. Two-Equation Model}

In the classic water-hammer theory, only 1-DOF is described and the distensibility of the pipe in the radial direction is taken into account neglecting the radial inertia of the pipe-wall and the fluid, and assuming a quasi-steady linear-elastic circumferential deformation of the pipe-wall.

On the one side, if inertial terms (proportional to $\partial W / \partial t$ ) are neglected in the momentum equation of the 2-DOF, Equation (3) becomes the well-known hoop stress formula:

$$
\sigma_{\theta}=\frac{r p}{e}
$$

Applying time partial derivative to both sides of Equation (A1) and expanding differential terms, one obtains:

$$
\frac{\partial \sigma_{\theta}}{\partial t}=\frac{p}{e} \frac{\partial r}{\partial t}+\frac{r}{e} \frac{\partial p}{\partial t}
$$

The left-hand side of Equation (A2) can be written in terms of circumferential strain:

$$
E \frac{\partial \epsilon_{\theta}}{\partial t}=\frac{p}{e} \frac{\partial r}{\partial t}+\frac{r}{e} \frac{\partial p}{\partial t}
$$

and knowing that $\epsilon_{\theta}=\partial r / r$, one gets:

$$
E \frac{\partial \epsilon_{\theta}}{\partial t}=\frac{p r}{e} \frac{\partial \epsilon_{\theta}}{\partial t}+\frac{r}{e} \frac{\partial p}{\partial t}
$$

Rearranging Equation (A4) and assuming $\frac{p r}{e}<<E$, one obtains:

$$
\frac{\partial \epsilon_{\theta}}{\partial t}=\frac{r}{e E} \frac{\partial p}{\partial t}
$$

On the other side, the classic water-hammer theory does not consider any axial movement of the pipe. Hence, in Equation (4), $\partial U_{z} / \partial z=0$ and becomes:

$$
\frac{\partial \sigma_{\theta}}{\partial t}=E \frac{W}{r}
$$


which in terms of circumferential strain is:

$$
\frac{\partial \epsilon_{\theta}}{\partial t}=\frac{W}{r}
$$

Combining Equation (A5) with Equation (A7), an expression for the radial velocity of the pipe-wall, in a function of the inner pressure, is obtained:

$$
W=\frac{r^{2}}{e E} \frac{\partial p}{\partial t}
$$

Substituting Equation (A8) into the right-hand side of the continuity equation of the 1-DOF:

$$
\frac{1}{K} \frac{\partial p}{\partial t}+\frac{\partial V}{\partial z}=-\frac{2 r}{e E} \frac{\partial p}{\partial t}
$$

rearranging Equation (A9):

$$
\frac{\partial V}{\partial z}+\left(\frac{1}{K}+\frac{D}{e E}\right) \frac{\partial p}{\partial t}=0
$$

Finally, defining the elastic wave celerity as:

$$
a_{h}=\sqrt{\frac{K}{\rho_{f}\left(1+\frac{D K}{e E}\right)}},
$$

the continuity equation Equation (A12) for classic water-hammer theory is obtained:

$$
\frac{\partial V}{\partial z}+\frac{1}{\rho_{f} a_{h}^{2}} \frac{\partial p}{\partial t}=0
$$

The fundamental system of equations of the classic water-hammer theory, neglecting damping mechanisms, is therefore composed by Equations (1) and (A12), forming the following system of Equations (A13):

$$
\text { two-equation model }\left\{\begin{array}{c}
\frac{\partial V}{\partial t}+\frac{1}{\rho_{f}} \frac{\partial p}{\partial z}=0 \\
\frac{\partial V}{\partial z}+\frac{1}{\rho_{f} a_{h}^{2}} \frac{\partial p}{\partial t}=0
\end{array}\right.
$$

If the acoustic wave celerity in the unconfined fluid is considered $\left(a_{1}=\sqrt{\frac{K}{\rho_{f}}}\right)$, Equations (1) and (A12) are equivalent. Hence, the only difference between 1-DOF wave propagation and classic water-hammer theory is determined by how the elastic wave celerity is defined. The first assumes an entirely rigid pipe, while the second takes into account the hoop distensibility of the pipe-wall.

\section{Appendix C. Four-Equation Model}

The four-equation model describes the 1-DOF (fluid surging) and 3-DOF (solid surging) of the pipe system and takes into account the 2-DOF (breathing) in a similar manner as the classic water-hammer theory. 


\section{Appendix C.1. Continuity in 1-DOF}

Subtracting from the 2-DOF continuity equation Poisson ratio times the 3-DOF continuity equation (i.e., Equation (4) -(6)), the following expression is obtained:

$$
\frac{\partial \sigma_{\theta}}{\partial t}-v \frac{\partial \sigma_{z}}{\partial t}=\left(1-v^{2}\right) E \frac{W}{r} .
$$

Notice that, dividing both sides of Equation (A14) by E, the left-hand side is actually the local time rate of change of the circumferential strain. Hoop stress can be written in terms of pressure according to Equation (A1), which is also valid in the present derivation. Thus, Equation (A15) is obtained:

$$
\frac{1}{e} \frac{\partial(p r)}{\partial t}-v \frac{\partial \sigma_{z}}{\partial t}=\left(1-v^{2}\right) E \frac{W}{r}
$$

expanding the differential term, as indicated below:

$$
\frac{p}{e} \frac{\partial r}{\partial t}+\frac{r}{e} \frac{\partial p}{\partial t}-v \frac{\partial \sigma_{z}}{\partial t}=\left(1-v^{2}\right) E \frac{W}{r},
$$

and by considering that $\frac{p}{e} \frac{\partial r}{\partial t}$ is negligible for low frequencies compared to other terms and by rearranging Equation (A16), one obtains:

$$
W=\frac{\frac{r^{2}}{e} \frac{\partial p}{\partial t}-r v \frac{\partial \sigma_{z}}{\partial t}}{\left(1-v^{2}\right) E}
$$

Substituting Equation (A17) into Equation (2) leads to:

$$
\frac{1}{K} \frac{\partial p}{\partial t}+\frac{\partial V}{\partial z}=-\frac{D}{e\left(1-v^{2}\right) E} \frac{\partial p}{\partial t}+\frac{2 v}{\left(1-v^{2}\right) E} \frac{\partial \sigma_{z}}{\partial t}
$$

neglecting second-order Poisson-ratio terms and rearranging Equation (A18), one gets:

$$
\frac{\partial V}{\partial z}+\left(\frac{1}{K}+\frac{D}{e E}\right) \frac{\partial p}{\partial t}=\frac{2 v}{E} \frac{\partial \sigma_{z}}{\partial t} .
$$

Finally, applying the definition of elastic wave celerity from Equation (A11), the continuity equation (Equation (A20)) for the 1-DOF of a four-equation model is obtained:

$$
\frac{\partial V}{\partial z}+\frac{1}{\rho_{f} a_{h}^{2}} \frac{\partial p}{\partial t}=\frac{2 v}{E} \frac{\partial \sigma_{z}}{\partial t} .
$$

Appendix C.2. Continuity in 3-DOF

Substituting Equation (A17) into Equation (6):

$$
\frac{\partial \sigma_{z}}{\partial t}-E \frac{\partial U_{z}}{\partial z}=\frac{\frac{v r}{e} \frac{\partial p}{\partial t}-v^{2} \frac{\partial \sigma_{z}}{\partial t}}{\left(1-v^{2}\right)},
$$

neglecting second order Poisson ratio terms and rearranging the continuity equation (Equation (A21)), one gets:

$$
\frac{\partial U_{z}}{\partial z}-\frac{1}{E} \frac{\sigma_{z}}{\partial t}=-\frac{v r}{e E} \frac{\partial p}{\partial t} .
$$

Finally, defining the acoustic wave speed in the pipe-wall as:

$$
a_{3}=\sqrt{\frac{E}{\rho_{p}}},
$$


and substituting Equation (A23) into Equation (A22), the continuity equation of the pipe-wall (Equation (A24)) for the four-equation model is obtained:

$$
\frac{\partial U_{z}}{\partial z}-\frac{1}{\rho_{p} a_{3}^{2}} \frac{\sigma_{z}}{\partial t}=-\frac{v r}{e E} \frac{\partial p}{\partial t}
$$

The four fundamental equations of a four-equation model are composed, therefore, of Equations (1), (A20), (5) and (A24). Forming the following system of Equations (A25):

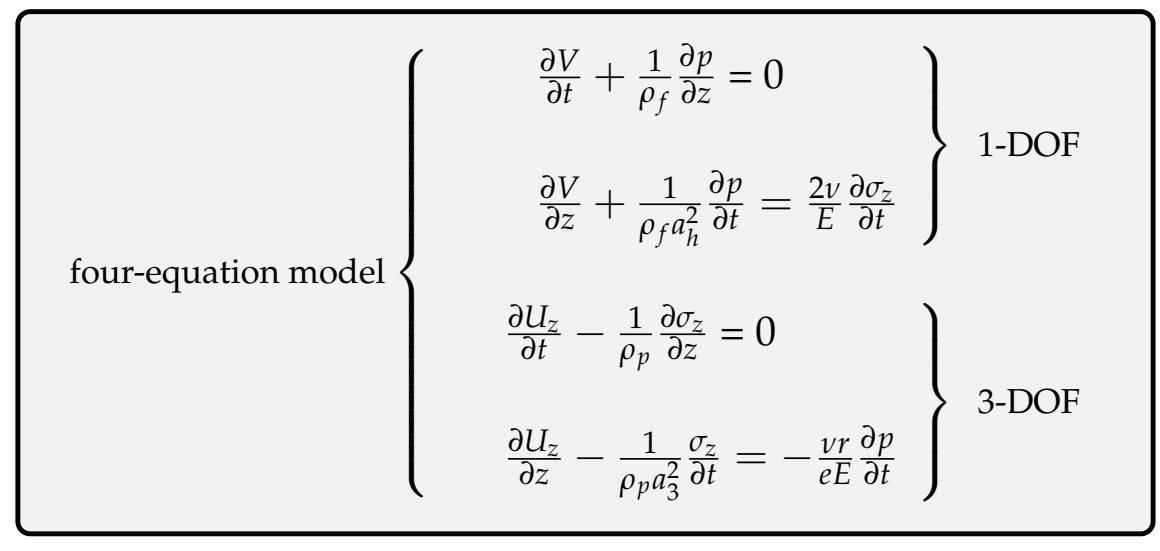

\section{References}

1. Korteweg, D. Ueber die Fortpflanzungsgeschwindigkeit des Schalles in elastischen Röhren. Annalen der Physik 1878, 241, 525-542. [CrossRef]

2. Helmholtz, H. Report on theoretical acoustics concerning works of the years 1848 and 1849. Gesammelte wissenschaftliche Abhandlungen 1882, 1, 233-255.

3. Skalak, R. An Extension of the Theory of Water Hammer. Ph.D. Thesis, Department of Civil Engineering and Engineering Mechanics Columbia Univiversity, New York, NY, USA, 1955.

4. Wilkinson, D. The Dynamic Response of Pipework Systems to Water Hammer; Central Electricity Generating Board: London, UK, 1977.

5. Walker, J.; Phillips, J. Pulse propagation in fluid-filled tubes. J. Appl. Mech. 1977, 44, 31-35. [CrossRef]

6. Valentin, R.A.; Phillips, J.W.; Walker, J.S. Reflection and Transmission of Fluid Transients at an Elbow; Technical Report; Argonne National Lab.: Chicago, IL, USA, 1979.

7. Wiggert, D.; Hatfield, F.; Stuckenbruck, S. Analysis of liquid and structural transients in piping by the method of characteristics. J. Fluids Eng. 1985, 109, 161-165 [CrossRef]

8. Wiggert, D. Coupled transient flow and structural motion in liquid-filled piping systems: A survey. In Proceedings of the ASME Pressure Vessels and Piping Conference, Chicago, IL, USA, 20-24 July 1986.

9. Joung, I.B.; Shin, Y. A new model on transient wave propagation in fluid-filled tubes. J. Press. Vessel Technol. 1987, 109, 88-93. [CrossRef]

10. Bürmann, W.; Thielen, H. Measurement and computation of dynamic reactive forces on pipes containing flow. 3R Int. 1988, 27, 434-440.

11. Wiggert, D.C.; Tijsseling, A.S. Fluid transients and Fluid-Structure Interaction in flexible liquid-filled piping. Appl. Mech. Rev. 2001, 54, 455-481. [CrossRef]

12. Tijsseling, A. Exact solution of linear hyperbolic four-equation system in axial liquid-pipe vibration. J. Fluids Struct. 2003, 18, 179-196. [CrossRef]

13. Wood, F.M. History of Water-Hammer; Number 65; Department of Civil Engineering, Queen's University: Kingston, ON, Canada, 1970.

14. Thorley, A. A survey of investigations into pressure surge phenomena. In Research Memorandum ML83; City University, Department of Mechanical Engineering: London, UK, 1976.

15. Anderson, A. Menabrea's note on waterhammer: 1858. J. Hydraul. Div. 1976, 102, $29-39$.

16. Tijsseling, A.S.; Anderson, A. Johannes von Kries and the history of water hammer. J. Hydraul. Eng. 2007, 133, 1-8. [CrossRef] 
17. Tijsseling, A.S.; Anderson, A. Thomas Young's research on fluid transients: 200 years on. In Proceedings of the BHR Group 2008 Conference on Pressure Surges, Edinburgh, UK, 14-16 May 2008; pp. 21-33.

18. Tijsseling, A.; Anderson, A. A. Isebree Moens and D.J. Korteweg: On the speed of propagation of waves in elastic tubes. In Proceedings of the 11th International Conference on Pressure Surges, Lisbon, Portugal, 24-26 October 2012; pp. 227-245.

19. Boulanger, A. Étude Sur la Propagation des Ondes Liquides Dans Les Tuyaux Élastiques; Tallandier: Paris, France, 1913; Volume 2.

20. Lambossy, P. Paper historique et critique sur le probleme de la propagation des ondes dans un liquide compressible enferme dans un tube elastique. Helv. Physiol. Pharmacol. Acta 1950, 8, 209-227. [PubMed]

21. Stecki, J.; Davis, D. Fluid transmission lines distributed parameter models part 1: A review of the state of the art. J. Power Energy 1986, 200, 215-228. [CrossRef]

22. Ghidaoui, M.S.; Zhao, M.; McInnis, D.A.; Axworthy, D.H. A review of water hammer theory and practice. Appl. Mech. Rev. 2005, 58, 49-76. [CrossRef]

23. Tijsseling, A. Fluid-Structure Interaction in liquid-filled pipe systems: A review. J. Fluids Struct. 1996, 10, 109-146. [CrossRef]

24. Li, S.; Karney, B.W.; Liu, G. FSI research in pipeline systems-A review of the literature. J. Fluids Struct. 2015, 57, 277-297. [CrossRef]

25. Giannopapa, C.G. Fluid Structure Interaction in Flexible Vessels. Ph.D. Thesis, University of London, King's College, London, UK, 2004.

26. Sinha, A. Vibration of Mechanical Systems; Cambridge University Press: Cambridge, UK, 2010; ISBN 13 978-1107694170.

27. Tijsseling, A.S.; Vardy, A.E. What is wave speed? In Proceedings of the 12th International Conference on Pressure Surges, Dublin, Ireland, 18-20 November 2015; pp. 343-360.

28. Ware, A.; Williamson, R. BLAZER: A RELAP5/MODI post processor to generate force-time history input data for structural computer codes. In Proceedings of the ASME Pressure Vessel and Piping Conference, Orlando, FL, USA, 27 June-1 July 1982; Volume 64.

29. Belytschko, T.; Karabin, M.; Lin, J. Fluid-Structure Interaction in waterhammer response of flexible piping. J. Press. Vessel Technol. 1986, 108, 249-255. [CrossRef]

30. A-Moneim, M.; Chang, Y. Comparison of Icepel code predictions with straight flexible pipe experiments. Nucl. Eng. Des. 1978, 49, 187-196. [CrossRef]

31. Romander, C.; Schwer, L.; Cagliostro, D. Response of water-filled thin-walled pipes to pressure pulses: Experiments and analysis. J. Press. Vessel Technol. 1980, 102, 56-61. [CrossRef]

32. Kulak, R. Some Aspects of Fluid-Structure Coupling; Technical Report; Argonne National Laboratory: Argonne, IL, USA, 1982.

33. Kulak, R. Three-dimensional fluid-structure coupling in transient analysis. Comput. Struct. 1985, 21, 529-542. [CrossRef]

34. Erath, W.; Nowotny, B.; Maetz, J. Simultaneous coupling of the calculation of pressure waves and pipe oscillations. 3R Int. 1998, 37, 501-508.

35. Erath, W.; Nowotny, B.; Maetz, J. Modelling the fluid structure interaction produced by a waterhammer during shutdown of high-pressure pumps. Nucl. Eng. Des. 1999, 193, 283-296. [CrossRef]

36. Bietenbeck, F.; Petruschke, W.; Wuennenberg, H. Piping response due to blowdown significant parameters for a comparison of experimental and analytical results. In Proceedings of the 8th International Conference on Structural Mechanics in Reactor Technology, Brussels, Belgium, 19-23 August 1985.

37. Mueller, W. Uncoupled and coupled analysis of a large HDR pipe. In Proceedings of the Transactions of the 9th International Conference on Structural Mechanics in Reactor Technology, Lausanne, Switzerland, 17-21 August 1987.

38. Casadei, F.; Halleux, J.; Sala, A.; Chille, F. Transient fluid-Structure interaction algorithms for large industrial applications. Comput. Methods Appl. Mech. Eng. 2001, 190, 3081-3110. [CrossRef]

39. Simão, M.; Mora, J.; Ramos, H.M. Fluid-structure interaction with different coupled models to analyse an accident occurring in a water supply system. Res. Technol. Aqua 2015, 64, 302-315. [CrossRef]

40. Simão, M.; Mora-Rodriguez, J.; Ramos, H.M. Interaction between hydraulic transient events and structure vibration. In Proceedings of the 12th International Conference on Pressure Surges, Dublin, Ireland, 18-20 November 2015; pp. 273-286. 
41. Menabrea, L.F. Note sur les effects de choc de l'eau dans les conduites. Comptes Rendus Hebd. Seances de L'Academie des Sci. 1858, 47, 221-224.

42. Von Kries, J. Ueber die Beziehungen zwischen Druck und Geschwindigkeit, welche bei der Wellenbewegung in elastischen Schlaff fluchen bestehen. On the relations between pressure and velocity, which exist in the wavelike motion in elastic tubes. Festschrift der 1883, 56, 67-88.

43. Frizell, J. Pressures resulting from changes of velocity of water in pipes. Trans. Am. Soc. Civ. Eng. 1898, $39,1-7$.

44. Allievi, L. Teoria Generale Del Moto Perturbato Dell'acqua Nei Tubi in Pressione (Colpo D'ariete). Translated into English by EE Halmos (1925); American Society of Civil Engineers: Reston, VA, USA, 1902.

45. Joukowsky, N. On the hydraulic hammer in water supply pipes. Proc. Am. Water Works Assoc. 1904, 24, 341-424.

46. Halliwell, A. Velocity of a water-hammer wave in an elastic pipe. J. Hydraul. Div. 1963, 89, 1-21.

47. Schwarz, W. Druckstoßberechnung unter Berücksichtigung der Radial-und Längsverschiebungen der Rohrwandung. Ph.D. Thesis, Universität Stuttgart, Institut fuür Wasserbau, Mitteilungen, Heft 43, Stuttgart, Germany, 1978; ISSN 0343-1150.

48. Wiggert, D. Fluid-Structure Interaction in piping systems. In Proceedings of the Druckstoßberechnung von Rohrleitungssystemen, Haus der Technik, Essen, Germany, December 1983.

49. Kojima, E.; Shinada, M. Dynamic behavior of a finite length straight pipe subject to water-hammer (2nd report, for a very thin-walled pipe). Trans. Jpn. Soc. Mech. Eng. Ser. B 1988, 54, 3346-3353. [CrossRef]

50. Bürmann, W.; Thielen, H. Untersuchung der Bewegung des Befüllstrangs einer Salzkaverne. (Study on the motion of the filling string of a saline cavern.). 3R Int. 1988, 27, 275-281.

51. Lavooij, C.; Tijsseling, A.S. Fluid-Structure Interaction in liquid-filled piping systems. J. Fluids Struct. 1991, 5, 573-595. [CrossRef]

52. Zhang, X.; Huang, S.; Wang, Y. The FEM of fluid structure interaction in piping pressure transients. In Proceedings of the First International Conference on Flow Interaction, Hong Kong, 5-9 September 1994; pp. 532-535.

53. Vardy, A.; Fan, D.; Tijsseling, A. Fluid-Structure Interaction in a T-piece pipe. J. Fluids Struct. 1996, 10, 763-786. [CrossRef]

54. Li, Q.; Yang, K.; Zhang, L. Analytical solution for Fluid-Structure Interaction in liquid-filled pipes subjected to impact-induced water hammer. J. Eng. Mech. 2003, 129, 1408-1417. [CrossRef]

55. Gale, J.; Tiselj, I. Applicability of the Godunov's method for fundamental four-equation FSI model. In Proceedings of the International Conference on Nuclear Energy for New Europe, Bled, Slovenia, 5-8 September 2005.

56. Loh, K.; Tijsseling, A.S. Water Hammer (With FSI): Exact Solution Parallelization and Application. In Proceedings of the ASME 2014 Pressure Vessels and Piping Conference; American Society of Mechanical Engineers: New York, NY, USA, 2014; p. V005T11A016.

57. Ferras, D.; Manso, P.A.; Schleiss, A.J.; Covas, D.I. Fluid-structure interaction in straight pipelines with different anchoring conditions. J. Sound Vib. 2017, 394, 348-365. [CrossRef]

58. Kellner, A.; Voss, J.; Schoenfelder, C. Fluid-Structure Interaction in piping systems: Experiment and theory. In Proceedings of the 7th International Conference on Structural Mechanics in Reactor Technology, Chicago, IL, USA, 22-26 August 1983; Volume B.

59. Gorman, D.; Reese, J.; Zhang, Y. Vibration of a flexible pipe conveying viscous pulsating fluid flow. J. Sound Vib. 2000, 230, 379-392. [CrossRef]

60. Tijsseling, A. Water hammer with fluid-structure interaction in thick-walled pipes. Comput. Struct. 2007, 85, 844-851. [CrossRef]

61. Regetz, J. An Experimental Determination of the Dynamic Response of a Long Hydraulic Line; Technical Note; National Aeronautics and Space Administration (NASA): Washington, DC, USA, 1960.

62. Wood, D.J.; Chao, S. Effect of pipeline junctions on water hammer surges. Trans. Eng. J. 1971, 97, 441-457.

63. A-Moneim, M.; Chang, Y. Comparison of ICEPEL predictions with single-elbow flexible piping system experiment. J. Press. Vessel Technol. 1979, 101, 142-148. [CrossRef]

64. Hu, C.K.; Phillips, J. Pulse propagation in fluid-filled elastic curved tubes. J. Press. Vessel Technol. 1981, 103, 43-49. [CrossRef] 
65. Tijsseling, A.; Fan, D.; Vardy, A. Transient Fluid-Structure Interaction and cavitation in a single-elbow pipe system. In Proceedings of the First International Conference on Flow Interaction, Hong Kong, 5-9 September 1994; pp. 346-349.

66. Tijsseling, A.; Vardy, A.; Fan, D. Fluid-Structure Interaction and cavitation in a single-elbow pipe system. J. Fluids Struct. 1996, 10, 395-420. [CrossRef]

67. Tijsseling, A.; Heinsbroek, A. The influence of bend motion on waterhammer pressures and pipe stresses. In Proceedings of the 3rd ASME \& JSME Joint Fluids Engineering Conference, Symposium S-290 Water Hammer, San Francisco, CA, USA, July 1999; Volume 248, pp. 1-7.

68. Gale, J.; Tiselj, I. Eight equation model for arbitrary shaped pipe conveying fluid. In Proceedings of the International Conference on Nuclear Energy for New Europe, Portoroz, Slovenia, 18-21 September 2006.

69. Weijde, P. Prediction of pressure surges and dynamic forces in pipeline systems, influence of system vibrations on pressures and dynamic forces (fluid-structure interaction). In Proceedings of the Symposium on Pipelines, Utrecht, The Netherlands, November 1985; pp. 327-335.

70. Tijsseling, A.; Lavooij, C. Waterhammer with Fluid-Structure Interaction. Appl. Sci. Res. 1990, 47, $273-285$. [CrossRef]

71. Lavooij, C.; Tijsseling, A.S. Fluid-Structure Interaction in compliant piping systems. In Proceedings of the 6th International Conference on Pressure Surges, Cambridge, UK, 4-6 October 1989; pp. 85-100.

72. Kruisbrink, A. Modelling of safety and relief valves in waterhammer computer codes. In Proceedings of the 3rd International Conference on Developments in Valves and Actuators for Fluid Control, BHRA, Bournemouth, UK, 27-29 March 1990; pp. 137-149.

73. Bettinali, F.; Molinaro, P.; Ciccotelli, M.; Micelotta, A. Transient analysis in piping networks including Fluid-Structure Interaction and cavitation effects. Trans. SMiRT 1991, 11, 565-570.

74. Heinsbroek, A. Fluid-Structure Interaction in non-rigid pipeline systems. Nucl. Eng. Des. 1997, 172, $123-135$. [CrossRef]

75. Young, T. Hydraulic investigations, subservient to an intended Croonian lecture on the motion of the blood. Philos. Trans. R. Soc. Lond. 1808, 98, 164-186. [CrossRef]

76. Weber, W. Theory of waves propagating in water or other incompressible liquids contained in elastic pipes. Math. Phys. 1866, 18, 353-357.

77. Resal, H. Note on the small motions of incompressible fluids in an elastic tube. J. Math. Pures Appl. 1876, 3, 342-344.

78. Moens, A. The Pulsation; Brill: Leiden, The Netherlands, 1878.

79. Ghidaoui, M.S. On the fundamental equations of water hammer. Urban Water J. 2004, 1, 71-83. [CrossRef]

80. Chaudhry, M.H. Applied Hydraulic Transients; Springer: New York, NY, USA, 2014; ISBN 978-1-4614-8537-7

81. Vardy, A.E.; Tijsseling, A.S. Method of characteristics: (Why) is it so good? In Proceedings of the 12th International Conference on Pressure Surges, Dublin, Ireland, 18-20 November 2015; pp. 327-341.

82. Gromeka, I. On the velocity of propagation of wave-like motion of fluids in elastic tubes. Phys. Math. Sect. Sci. Soc. 1883, 5, 1-19.

83. Lamb, H. On the velocity of sound in a tube, as affected by the elasticity of the walls. Manch. Mem. 1898, $42,1-16$.

84. Thorley, A. Pressure transients in hydraulic pipelines. J. Basic Eng. 1969, 91, 453-460. [CrossRef]

85. Bürmann, W. Druckstossmessungen an koaxialen Rohren. (Water hammer measurements on coaxial pipes.). 3R Int. 1979, 18, 624-628.

86. Thielen, H.; Bürmann, W. Calculation and protection of pipe lines laid in the open against undue internal pressure and reactive forces resulting from water hammer. 3R Int. 1980, 19, 622-628.

87. Tijsseling, A.S.; Lambert, M.F.; Simpson, A.R.; Stephens, M.L.; Vítkovskỳ, J.P.; Bergant, A. Skalak's extended theory of water hammer. J. Sound Vib. 2008, 310, 718-728. [CrossRef]

88. Bürmann, W. Water hammer in coaxial pipe systems. J. Hydraul. Div. 1975, 101, 699-715.

89. Bürmann, W.; Feser, G.; Janson, H.; Thielen, H. Mathematical simulation of the dynamics of pipelines laid in the open in case of unsteady flows. In Report on the Measurements and Numerical Simulation of the Measurements on the Neckar Bridge; Bericht Nr. 623; Universität Karlsruhe, Institut fur Hydromechanik: Karlsruhe, Germany, 1985. 
90. Bürmann, W.; Feser, G.; Janson, H.; Thielen, H. Mathematical simulation of the dynamics of pipelines laid in the open in case of unsteady flows. In Report on the Second Measurements and Numerical Simulation; Bericht Nr. 64; Universität Karlsruhe, Institut fur Hydromechanik: Karlsruhe, Germany, 1986.

91. Bürmann, W.; Feser, G.; Janson, H.; Thielen, H. Pressure and acceleration measurements on the pipe bridge of a long-distance water main to study the piping dynamics in case of unsteady flow. $3 R$ Int. 1987, 26, 638-646.

92. Bürmann, W.; Feser, G.; Janson, H.; Thielen, H. Mathematical simulation of the dynamics of pipelines laid in the open in case of unsteady flows. In Report on the Measurements and Numerical Simulation of the Measurements on the Jade Transhipment Station; Bericht Nr. 622; Universität Karlsruhe, Institut fur Hydromechanik: Karlsruhe, Germany, 1986.

93. Vardy, A.; Alsarraj, A. Method of characteristics analysis of one-dimensional members. J. Sound Vib. 1989, 129, 477-487. [CrossRef]

94. Vardy, A.; Fan, D. Water hammer in a closed tube. In Proceedings of the 5th International Conference on Pressure Surges, Hanover, Germany, 22-24 September 1986.

95. Vardy, A.; Fan, D. Constitutive factors in transient internal flows. In Proceedings of the International Conference on Numerical Methods in Engineering: Theory and Applications (NUMETA 87), Swansea, UK, 6-10 July 1987; Volume 2.

96. Vardy, A.; Fan, D. Flexural waves in a closed tube. In Proceedings of the 6th International Conference on Pressure Surges, BHRA, Cambridge, UK, 4-6 October 1989; pp. 43-57.

97. Fan, D. Fluid-Structure Interaction in Internal Flows. Ph.D. Thesis, University of Dundee, Department of Civil Engineering, Dundee, UK, 1989.

98. Ellis, J. A study of pipe-liquid interaction following pump trip and check-valve closure in a pumping station. In Proceedings of the 3rd International Conference on Pressure Surges, Canterbury, UK, 25-27 March 1980; Volume 1.

99. Ferràs, D.; Manso, P.A.; Schleiss, A.J.; Covas, D.I. Experimental distinction of damping mechanisms during hydraulic transients in pipe flow. J. Fluids Struct. 2016, 66, 424-446. [CrossRef]

100. Elansary, A.; Contractor, D. Minimization of stresses and pressure surges. J. Press. Vessel Technol. 1990, 112, 311-316. [CrossRef]

101. Elansary, A.; Contractor, D. Valve closure: Method for controlling transients. J. Press. Vessel Technol. 1994, 116, 437-442. [CrossRef]

102. Elansary, A.S.; Chaudhry, M.H.; Silva, W. Numerical and experimental investigation of transient pipe flow. J. Hydraul. Res. 1994, 32, 689-706. [CrossRef]

103. Budny, D.D.; Wiggert, D.; Hatfield, F. The influence of structural damping on internal pressure during a transient pipe flow. J. Fluids Eng. 1991, 113, 424-429. [CrossRef]

104. Goldberg, D.E. Characteristics method using time-line interpolations. J. Hydraul. Eng. 1983, 109, $670-683$. [CrossRef]

105. Forsythe, G.E.; Wasow, W.R. Finite-Difference Methods for Partial Differential Equations; Wiley: Hoboken, NJ, USA, 1960; ISBN 13: 9780471266976.

106. Bouabdallah, S.; Massouh, F. Fluid-Structure Interaction in Hydraulic Networks; Aerospace Division Newsletter; American Society of Mechanical Engineers: New York, NY, USA, 1997; Volume AD-53-2, pp. 543-548.

107. Ghodhbani, A.; Hadj-Taïeb, E. Numerical Coupled Modeling of Water Hammer in Quasi-rigid Thin Pipes. In Design and Modeling of Mechanical Systems; Springer: Berlin, Germany, 2013; pp. 253-264, ISBN 978-3-642-37142-4.

108. Khalighi, F.; Ahmadi, A.; Keramat, A. Investigation of Fluid-structure Interaction by Explicit Central Finite Difference Methods. Int. J. Eng. Trans. B Appl. 2016, 29, 590-598.

109. Ferras, D.; Manso, P.; Covas, D.; Schleiss, A. Fluid-structure interaction in pipe coils during hydraulic transients. J. Hydraul. Res. 2017, 55, 491-505. [CrossRef]

110. Ferràs, D.; Covas, D.I.; Schleiss, A.J. Stress-strain analysis of a toric pipe for inner pressure loads. J. Fluids Struct. 2014, 51, 68-84. [CrossRef]

111. Keramat, A.; Tijsseling, A. Waterhammer with column separation, Fluid-Structure Interaction and unsteady friction in a viscoelastic pipe. In Proceedings of the International Conference on Pressure Surges, Lisbon, Portugal, 24-26 October 2012. 
112. Tijsseling, A.S. Exact computation of the axial vibration of two coupled liquid-filled pipes. In Proceedings of the ASME 2009 Pressure Vessels and Piping Conference, Prague, Czech Republic, 26-30 July 2009.

113. Xu, Y.; Jiao, Z. Exact solution of axial liquid-pipe vibration with time-line interpolation. J. Fluids Struct. 2017, 70, 500-518. [CrossRef]

114. Ferràs, D. Fluid-Structure Interaction During Hydraulic Transients in Pressurized Pipes: Experimental and Numerical Analyses. Ph.D. Thesis, École Polytechnique Fédérale de Lausanne EPFL, Lausanne, Switzerland, 2016.

115. Tijsseling, A. Poisson-coupling beat in extended waterhammer theory. In Proceedings of the 4th International Symposium on Fluid-Structure Interactions, Aeroelasticity, Flow-Induced Vibration and Noise, At Dallas, TX, USA, November 1997; Volume 53-2, pp. 529-532.

116. Borzi, A.; Propst, G. Numerical investigation of the Liebau phenomenon. Z. für Angew. Math. Physik ZAMP 2003, 54, 1050-1072. [CrossRef]

117. Tijsseling, A.S. An Overview of Fluid-Structure Interaction Experiments in Single-Elbow Pipe Systems; CASA-Report 1616; TUE: Eindhoven, The Netherlands, 2016.

118. Swaffield, J. The influence of bends on fluid transients propagated in incompressible pipe flow. Proc. Inst. Mech. Eng. 1968, 183, 603-614. [CrossRef]

119. Otwell, R. The Effect of Elbow Restraint on Pressure Transients. Ph.D. Thesis, Michigan State University, Department of Civil and Sanitary Engineering, East Lansing, NI, USA, 1984.

120. Wiggert, D.; Otwell, R.; Hatfield, F. The effect of elbow restraint on pressure transients. J. Fluids Eng. 1985, 107, 402-406. [CrossRef]

121. Tijsseling, A.; Vaugrante, P. FSI in L-shaped and T-shaped pipe systems. In Proceedings of the 10th International Meeting of the IAHR Work Group on the Behaviour of Hydraulic Machinery under Steady Oscillatory Conditions, Trondheim, Norway, 26-28 June 2001.

122. Steens, N.; Pan, J. Transient vibration in a simple fluid carrying pipe system. Acoust. Aust. 2008, 36, $15-21$.

123. Altstadt, E.; Carl, H.; Prasser, H.; WeiB, R. Fluid-Structure Interaction during artificially induced water hammers in a tube with a bend-Experiments and analyses. Multiph. Sci. Technol. 2008, 20, 213-238. [CrossRef]

124. Simão, M.; Mora-Rodriguez, J.; Ramos, H.M. Mechanical Interaction in Pressurized Pipe Systems: Experiments and Numerical Models. Water 2015, 7, 6321-6350. [CrossRef]

125. Lesmez, M.W.; Wiggert, D.; Hatfield, F. Modal analysis of vibrations in liquid-filled piping systems. J. Fluids Eng. 1990, 112, 311-318. [CrossRef]

126. Obradović, P. Fluid-Structure Interactions: An accident which has demonstrated the necessity for FSI analysis. In Proceedings of the 15th IAHR Symposium on Hydraulic Machinery and Cavitation, Belgrade, Yugoslavia, 14 September 1990.

127. Kruisbrink, A.; Heinsbroek, A. Fluid-Structure Interaction in non-rigid pipeline systems—Large scale validation tests. In Proceedings of the International Conference on Pipeline Systems, Manchester, England, 1992, pp. 151-164.

128. Heinsbroek, A.; Kruisbrink, A. Fluid-Structure Interaction in non-rigid pipeline systems-large scale validation experiments. In Proceedings of the 12th International Conference on Structural Mechanics in Reactor Technology (SMiRT), Stuttgart, Germany, 15-20 August 1993.

129. Lavooij, C. FLUSTRIN: Benchmark Problems; Delft Hydraulics: Delft, The Netherlands, 1987.

130. Ahmadi, A.; Keramat, A. Investigation of fluid-structure interaction with various types of junction coupling. J. Fluids Struct. 2010, 26, 1123-1141. [CrossRef]

131. Keramat, A.; Tijsseling, A.; Hou, Q.; Ahmadi, A. Fluid-Structure Interaction with Pipe-Wall Viscoelasticity During Water Hammer; Elsevier: Amsterdam, The Netherlands, 2012; Volume 28, pp. 434-455.

132. Kochupillai, J.; Ganesan, N.; Padmanabhan, C. A new finite element formulation based on the velocity of flow for water hammer problems. Int. J. Press. Vessels Pip. 2005, 82, 1-14. [CrossRef]

133. Hatfield, F.; Wiggert, D. Harmonic analysis of coupled fluid and piping. In Proceedings of the ASCE Engineering Mechanics Speciality Conference, West Lafayette, IN, USA, 23-25 May 1983; pp. 180-192.

134. Davidson, L.; Samsury, D. Liquid-structure coupling in curved pipes-I. Shock Vib. Bull. 1969, 40, $197-207$.

135. Davidson, L.; Samsury, D. Liquid-structure coupling in curved pipes-II. Shock Vib. Bull. 1972, 43, $123-135$.

136. Clark, R.; Reissner, E. Deformations and stresses in Bourdon tubes. J. Appl. Phys. 1950, 21, $1340-1341$. [CrossRef] 
137. Reissner, E.; Clark, R.; Gilroy, R. Stresses and Deformations of Torsional Shells of an Elliptical Cross Section with Applications to the Problems of Bending of Curved Tubes and the Bourdon Gage. Trans. ASME J. Appl. Mech. 1952, pp. 37-48.

138. Bathe, K.; Almeida, C. A simple and effective pipe elbow element-linear analysis. J. Appl. Mech. 1980, 47, 93-100. [CrossRef]

139. Bathe, K.; Almeida, C. A simple and effective pipe elbow element-interaction effects. J. Appl. Mech. 1982, 49, 165-171. [CrossRef]

140. Tentarelli, S. Propagation of Noise and Vibration in Complex Hydraulic Tubing Systems. Ph.D. Thesis, Lehigh University, Department of Mechanical Engineering, Bethlehem, PA, USA, 1990.

141. Brown, F.T.; Tentarelli, S.C. Dynamic behavior of complex fluid-filled tubing systems, Part 1: Tubing analysis. J. Dyn. Syst. Meas. Control 2001, 123, 71-77. [CrossRef]

142. Tentarelli, S.C.; Brown, F.T. Dynamic behavior of complex fluid-filled tubing systems—Part 2: System analysis. J. Dyn. Syst. Meas. Control 2001, 123, 78-84. [CrossRef]

143. Budny, D.; Hatfield, F.; Wiggert, D. An experimental study on the influence of structural damping on internal fluid pressure during a transient flow. J. Press. Vessel Technol. 1990, 112, 284-290. [CrossRef]

144. Housner, G. Bending vibrations of a pipe line containing flowing fluid. J. Appl. Mech. Trans. ASME 1952, 19, 205-208.

145. Gregory, R.; Païdoussis, M. Unstable oscillation of tubular cantilevers conveying fluid. In Proceedings of the Royal Society of London A: Mathematical, Physical and Engineering Sciences, London, UK, 23 August 1966; Volume 293, pp. 512-527.

146. Païdoussis, M.P.; Issid, N. Dynamic stability of pipes conveying fluid. J. Sound Vib. 1974, 33, $267-294$. [CrossRef]

147. Païdoussis, M.; Laithier, B. Dynamics of Timoshenko beams conveying fluid. J. Mech. Eng. Sci. 1976, 18, 210-220. [CrossRef]

148. Jendrzejczyk, J.; Chen, S. Experiments on tubes conveying fluid. Thin Walled Struct. 1985, 3, $109-134$. [CrossRef]

149. Païdoussis, M.P. Fluid-Structure Interactions: Slender Structures and Axial Flow; Academic Press: Cambridge, MA, USA, 2016; Volumes 1-2.

150. Leslie, D.; Vardy, A. Practical guidelines for fluid-structure interaction in pipelines: A review. In Proceedings of the 10th International Meeting of the Work Group on the Behaviour of Hydraulic Machinery under Steady Oscillatory Conditions, Trondheim, Norway, 26-28 June 2001.

151. Moussou, P.; Lafon, P.; Potapov, S.; Paulhiac, L.; Tijsseling, A. Industrial cases of FSI due to internal flows. In Proceedings of the 9th International Conference on Pressure Surges, Chester, UK, 24-26 March 2004; Volume 1, pp. 13-31.

152. Almeida, A.; Pinto, A. A special case of transient forces on pipeline supports due to water hammer effects. In Proceedings of the 5th International Conference on Pressure Surges, Hanover, Germany, 22-24 September 1986; Volome 2224, p. 2734.

153. Hamilton, M.; Taylor, G. Pressure surge-Case studies. In Proceedings of the 7th International Conference on Pressure Surges and Fluid Transients in Pipelines and Open Channels, Harrogate, UK, 16-18 April 1994; pp. 15-27.

154. Hamilton, M.; Taylor, G. Pressure surge-Criteria for acceptability. In Proceedings of the 7th International Conference on Pressure Surges and Fluid Transients in Pipelines and Open Channels, Harrogate, UK, 16-18 April 1994; pp. 343-362.

155. Locher, F.; Huntamer, J.; O'Sullivan, J. Caution: Pressure surges in process and industrial systems may be fatal. In Proceedings of the BHR Group Conference Series; Professional Engineering Publishing: Bury St. Edmunds, UK, 2000; Volume 39, pp. 3-18.

156. Heinsbroek, A.; Tijsseling, A. The influence of support rigidity on waterhammer pressures and pipe stresses. In Proceedings of the 2nd International Conference on Water Pipeline Systems, Scotland, UK, 24-26 May 1994; pp. 17-30.

157. Tijsseling, A.; Vardy, A. Axial modelling and testing of a pipe rack. In Proceedings of the BHR Group Conference Series Publication, Harrogate, UK, 16-18 April 1996; Volume 19, pp. 363-384.

158. Ferràs, D.; Manso, P.A.; Schleiss, A.J.; Covas, D.I. Fluid-Structure Interaction in straight pipelines: Friction coupling mechanisms. Comput. Struct. 2016, 175, 74-90. [CrossRef] 
159. Zanganeh, R.; Ahmadi, A.; Keramat, A. Fluid-structure interaction with viscoelastic supports during waterhammer in a pipeline. J. Fluids Struct. 2015, 54, 215-234. [CrossRef]

160. Wu, J.S.; Shih, P.Y. The dynamic analysis of a multispan fluid-conveying pipe subjected to external load. J. Sound Vib. 2001, 239, 201-215. [CrossRef]

161. Yang, K.; Li, Q.; Zhang, L. Longitudinal vibration analysis of multi-span liquid-filled pipelines with rigid constraints. J. Sound Vib. 2004, 273, 125-147. [CrossRef]

162. Moser, M.; Heckl, M.; Ginters, K.H. On Wave Propagation of Fluid-Filled Circular Cylindrical Tubes. Acustica 1986, 60, 34-44.

163. Kwong, A.; Edge, K. Structure-borne noise prediction in liquid-conveying pipe systems. J. Syst. Control Eng. 1996, 210, 189-200. [CrossRef]

164. Kwong, A.; Edge, K. A method to reduce noise in hydraulic systems by optimizing pipe clamp locations. J. Syst. Control Eng. 1998, 212, 267-280. [CrossRef]

165. De Jong, C. Analysis of Pulsations and Vibrations in Fluid-Filled Pipe Systems. Ph.D. Thesis, Technische Universiteit Eindhoven, Eindhoven, The Netherlands, 1994.

166. Janssens, M.; Verheij, J.; Thompson, D. The use of an equivalent forces method for the experimental quantification of structural sound transmission in ships. J. Sound Vib. 1999, 226, 305-328. [CrossRef]

167. Chen, C.C. Noise and vibration in complex hydraulic tubing systemss. In Continuum Mechanics-Progress in Fundamentals and Engineering Applications; Gan, Y., Ed.; Intech Open Access Publisher: London, UK, 2012; ISBN 978-953-51- 0447-6.

168. Tijsseling, A.; Vardy, A. On the suppression of coupled liquid/pipe vibrations. In Hydraulic Machinery and Cavitation; Springer: Berlin, Germany, 1996; pp. 945-954.

169. Hachem, F.E.; Schleiss, A.J. Effect of drop in pipe wall stiffness on water-hammer speed and attenuation. J. Hydraul. Res. 2012, 50, 218-227. [CrossRef]

170. Koo, G.; Park, Y. Vibration reduction by using periodic supports in a piping system. J. Sound Vib. 1998, 210, 53-68. [CrossRef]

171. Young, F.; Hunter, S. Hydraulic Transients in Liquid-Filled Pipelines During Earthquakes. Lifeline Earthquake Engineering Buried Pipelines, Seismic Risk and Instrumentation; American Society of Mechanical Engineers: New York, NY, USA, 1979.

172. Lo Frano, R.; Forasassi, G. Preliminary assessment of the Fluid-Structure Interaction effects in a GEN IV LMR. In Proceedings of the International Conference on Heat Transfer, Fluid Mechanics and Thermodynamics, Malta, 16-18 July 2012.

173. Mitsume, N.; Yoshimura, S.; Murotani, K.; Yamada, T. Improved MPS-FE Fluid-Structure Interaction coupled method with MPS polygon wall boundary model. Comput. Model. Eng. Sci. 2014, 101, $229-247$.

174. Hara, F. Seismic vibration analysis of Fluid-Structure Interaction in LMFBR piping systems. J. Press. Vessel Technol. 1988, 110, 177-181. [CrossRef]

175. Hatfield, F.; Wiggert, D. Seismic pressure surges in liquid-filled pipelines. J. Press. Vessel Technol. 1990, 112, 279-283. [CrossRef]

176. Blade, R.J.; Lewis, W.; Goodykoontz, J.H. Study of a Sinusoidally Perturbed Flow in a Line Including a 90 Degree Elbow with Flexible Supports; National Aeronautics and Space Administration (NASA), Lewis Research Center: Cleveland, OH, USA, 1962.

177. Steelant, J. Multi-phase fluid-hammer in aerospace applications. In Proceedings of the 12th International Conference on Pressure Surges, Dublin, Ireland, 18-20 November 2015; pp. 21-31.

178. Bombardieri, C.; Traudt, T.; Manfletti, C. Experimental and Numerical Analysis of Water Hammer During the Filling Process of Pipelines. In Proceedings of the Space Propulsion Conference, Cologne, Germany, 18-22 May 2014.

179. McDonald, D.A. Blood Flow in Arteries; Williams \& Wilkins: Baltimore, MD, USA, 1974; ISBN 139780713142136.

180. Nakoryakov, V.; Sobolev, V.; Shrieber, I.; Shtivel'Man, B.Y. Water hammer and propagation of perturbations in elastic fluid-filled pipes. Fluid Dyn. 1976, 11, 493-498. [CrossRef]

181. Anderson, A.; Johnson, G. Effect of Tube Ovalling on Pressure Wave Propagation Speed. J. Eng. Med. 1990, 204, 245-251. [CrossRef] [PubMed]

182. Sherwin, S.; Franke, V.; Peiró, J.; Parker, K. One-dimensional modelling of a vascular network in space-time variables. J. Eng. Math. 2003, 47, 217-250. [CrossRef] 
183. Van de Vosse, F.N.; Stergiopulos, N. Pulse wave propagation in the arterial tree. Annu. Rev. Fluid Mech. 2011, 43, 467-499. [CrossRef]

184. Nichols, W.; O'Rourke, M.; Vlachopoulos, C. McDonald's Blood Flow in Arteries: Theoretical, Experimental and Clinical Principles; CRC Press: Boca Raton, FL, USA, 2011; ISBN 9780340985014.

185. Alastruey, J.; Parker, K.H.; Sherwin, S.J. Arterial pulse wave haemodynamics. In Proceedings of the 11th International Conference on Pressure Surges, Lisbon, Portugal, 24-26 October 2012; pp. 401-442.

186. Wathen, A.; Galdi, G.; Rannacher, R.; Robertson, A.; Turek, S. Hemodynamical Flows: Modeling, Analysis and Simulation; Springer: Berlin, Germany, 2009; ISBN 978-3-7643-7805-9.

187. Janela, J.; Moura, A.; Sequeira, A. A 3D non-Newtonian fluid-structure interaction model for blood flow in arteries. J. Comput. Appl. Math. 2010, 234, 2783-2791. [CrossRef]

188. Simão, M.; Ferreira, J.; Mora-Rodriguez, J.; Ramos, H. Identification of DVT diseases using numerical simulations. Med. Biol. Eng. Comput. 2016, 54, 1591-1609. [CrossRef] [PubMed]

189. Jaeger, C.; Kerr, L.; Wylie, E. Water hammer effects in power conduits. Civ. Eng. Public Works Rev. 1948, 23, 500-503.

190. Bergant, A.; Simpson, A.R.; Tijsseling, A.S. Water hammer with column separation: A review of research in the twentieth century. J. Fluids Struct. 2006, 22, 135-171. [CrossRef]

191. Wang, C.; Pizzica, P.; Gvildys, J.; Spencer, B. Analysis of Fluid-Structure Interaction and Structural Response of Chernobyl-4 Reactor; Technical Report; Argonne National Lab.: Argonn, IL, USA, 1989.

192. Simão, M.; Mora-Rodriguez, J.; Ramos, H.M. Dynamic response behind an accident occurred in a main WSS. Eur. J. Environ. Civ. Eng. 2016, 22, 267-287. [CrossRef]

193. Leishear, R.A. Nuclear power plant fires and explosions, IV, water hammer explosions mechanisms. In Proceedings of the ASME 2017 Pressure Vessels and Piping Conference, Waikoloa, HI, USA, 16-20 July 2017.

194. Bonin, C. Water-hammer damage to Oigawa power station. J. Eng. Power 1960, 82, 111-116. [CrossRef]

195. Trenkle, C.J. Failure of Riveted and Forge-Welded Penstock. J. Energy Div. 1979, 105, 93-102.

196. Almeida, A.; Ramos, H. Water supply operation: Diagnosis and reliability analysis in a Lisbon pumping system. J. Water Suppl. Res. Technol. Aqua 2010, 59, 66-78. [CrossRef]

197. Vecchio, R.S.; Sinha, S.K.; Bruck, P.M.; Esselman, T.C.; Zysk, G. The 2007 New York City steam explosion: Post-accident analysis. In Proceedings of the 12th International Conference on Pressure Surges, Dublin, Ireland, 18-20 November 2015; pp. 7-17.

198. Adamkowski, A. Case study: Lapino powerplant penstock failure. J. Hydraul. Eng. 2001, 127, 547-555. [CrossRef]

199. Meserve, R.A. Safety Issues at the Defense Production Reactors: A Report to the US Department of Energy; National Academies: Washington, DC, USA, 1987; ISBN-13 9780000001542.

200. Vardy, A.; Alsarraj, A. Coupled axial and flexural vibration of 1-D members. J. Sound Vib. 1991, 148, $25-39$. [CrossRef]

201. Fan, D.; Vardy, A. Waterhammer including Fluid-Structure Interactions. In Proceedings of the First International Conference on Flow Interaction, Hong Kong, 5-9 September 1994, pp. 439-442.

202. Krause, N.; Goldsmith, W.; Sackman, J. Transients in tubes containing liquids. Int. J. Mech. Sci. 1977, 19, 53-68. [CrossRef]

203. Barez, F.; Goldsmith, W.; Sackman, J. Longitudinal waves in liquid-filled tubes I: Theory. Int. J. Mech. Sci. 1979, 21, 213-221. [CrossRef]

204. Wood, D.J. A study of the response of coupled liquid flow-structural systems subjected to periodic disturbances. J. Basic Eng. 1968, 90, 532-540. [CrossRef]

205. Wood, D.J. Influence of line motion on waterhammer pressures. J. Hydraul. Div. 1969, 95, 941-960.

(C) 2018 by the authors. Licensee MDPI, Basel, Switzerland. This article is an open access article distributed under the terms and conditions of the Creative Commons Attribution (CC BY) license (http:/ / creativecommons.org/licenses/by/4.0/). 